Research Article

\title{
Time-Dependent Reliability Analysis of RC Deep Beams considering Linear/Nonlinear Creep and Shrinkage Using ANFIS Network and MCS
}

\author{
Seyed Bahram Beheshti Aval (iD) and Mohsen Ghabdian \\ Department of Civil Engineering, K. N. Toosi University of Technology, Tehran 1996715433, Iran \\ Correspondence should be addressed to Seyed Bahram Beheshti Aval; beheshti@kntu.ac.ir
}

Received 10 February 2019; Revised 25 May 2019; Accepted 16 June 2019; Published 2 July 2019

Academic Editor: Lukasz Sadowski

Copyright (c) 2019 Seyed Bahram Beheshti Aval and Mohsen Ghabdian. This is an open access article distributed under the Creative Commons Attribution License, which permits unrestricted use, distribution, and reproduction in any medium, provided the original work is properly cited.

\begin{abstract}
This paper comprehensively studies the effects of linear and nonlinear creep and shrinkage on shear strength and deformation of reinforced concrete $(\mathrm{RC})$ deep beams through a time-dependent reliability analysis framework. The three-dimensional finite element-based program of ABAQUS was used to model RC deep beams. A viscoelastic approach was adopted to model linear creep and shrinkage by a user-defined material model developed and implemented in user subroutines UMAT and UEXPAN. The software was initially examined using two experimental results for short/long-term behavior of shallow and deep concrete beams. In the nonlinear range, creep was taken into account by the affinity hypothesis theorem to consider the effect of high-level sustained loading. Due to the complicated and time-consuming nature of the finite element method (FEM), adaptive neuro-fuzzy inference system (ANFIS) and Monte Carlo simulation (MCS) replaced these complex analyses. Finally, based on the numerical results obtained from the analyses of case study samples, it was concluded that, in a serviceability limit state, for RC deep beams, the probability of failure was reduced to less than one-fifth that for the shallow beams. On the contrary, in a strength limit state, a safety factor of about 1.7 1.8 could be considered for the effect of sustained high-level loading on the shear strength of RC deep beams.
\end{abstract}

\section{Introduction}

The role of RC deep beams in bearing huge gravitational loads (such as above the entrances to high-rise RC buildings with tubular structural systems) makes these members a vital structural element. Therefore, they have been the subject of extensive research studies to understand their performance within the linear and nonlinear ranges of behavior [1]. However, although a couple of studies have addressed the effects of linear/nonlinear creep and shrinkage on shallow beams and columns $[2,3]$, so far, these effects on the behavior of concrete deep beams have remained understudied [4]. Creep and shrinkage are affected by many factors, including concrete mix $[5,6]$, loading level $[7,8]$, concrete strength [9], loading time, geometric properties, construction method, and environmental conditions [10]. Because of the significant violating effect of the spreading strain on cross sections of shallow beams in plane fashion, prediction of the effects of creep and shrinkage on time-dependent reliability of deep concrete beam seems noteworthy to all professional designers [4]. In the present study, the scope of the reliability analysis is extended to linear and nonlinear creep and shrinkage in RC deep beams. Many researchers have conducted time-dependent reliability analysis of concrete structures under induced defects [11], corrosion [12], or their combination $[13,14]$. Consideration of creep and shrinkage in this type of analysis is a more recent trend in the literature. Stewart [15] developed a probabilistic model to estimate reliability of shallow concrete beams in the serviceability limit state. Guo et al. [16] presented a timedependent reliability assessment for PSC box-girder bridge including creep, shrinkage, and corrosion. Ma and Wang 
[17] implemented a time-dependent reliability for CFST arch bridge (Yajisha Bridge) considering creep, shrinkage, and corrosion.

Previous research has mainly focused on the study of linear/nonlinear creep and shrinkage in shallow RC beams, while their effects on deep beams are absent in the literature. Given this limitation, the present research focuses on three major developments as follows:

(1) In case of RC deep beams, in addition to the serviceability limit state, the strength limit state is also considered

(2) Effect of nonlinear creep is captured in both serviceability and strength limit states

(3) Time-dependent reliability analysis is extended to $\mathrm{RC}$ deep beams for the probabilistic nature of deterioration over time

The objective of this study is developing a comprehensive three-dimensional finite element model of RC deep beams in order to carry out time-dependent reliability analysis considering both linear and nonlinear creep and shrinkage. To build the prediction model, artificial neural networks (ANNs) have been developed to solve complex and more elaborated problems [18]. Unfortunately, the data required to construct ANN cannot be gathered directly from experimental results. Indeed, there are no data available in the literature obtained from the results of experimental evidence pertaining to the behavior of concrete deep beams subjected to linear/nonlinear creep and shrinkage effects. Thus, train, test, and checking data should be obtained indirectly using a verified finite element method (FEM). Because of modeling and computational costs, multiple applications of FEM are not practical and an artificial intelligent-based modeling technique such as neuro-fuzzy inference system (ANFIS) may be used instead of these time-consuming and complex analyses. So far, researchers have successfully used ANN and ANFIS in civil engineering problems $[19,20]$. A few research studies can be found in the literature which have focused on applying ANN and ANFIS to the prediction of strength and displacement of concrete structures including creep and shrinkage. Bal and BuyleBodin [21] applied a ANN to estimate the dimensional changes due to creep in 186 tests extracted from the RILEM (International Union of Laboratories and Experts in Construction Materials). Bilir et al. [22] used ANFIS for predicting the cracks widths of a specific mortar considering shrinkage as an important parameter in concrete behavior. Pendharkar et al. [23] presented a closed-form equation for estimating long-term deflection of high-rise concrete composite frames using the neural network. AlZewainy et al. [24] provided a statistical approach for predicting the long-term deflection of RC beams using ANN. Although both tools have widely been utilized with a satisfactory performance, researches have shown that, for many applications, ANFIS exhibits a greater performance than ANN and regression-based models do $[25,26]$. Thus, in this work, the ANFIS technique is used to predict the maximum deflection and shear strength of $\mathrm{RC}$ deep beams in relation to a twofold performance level of serviceability and ultimate shear strength limit states. The Monte Carlo simulation method is utilized to attain the probability of failure for each limit state condition.

\section{Analytical Modeling of Creep and Shrinkage of Concrete}

2.1. Linear and Nonlinear Concrete Creep and Shrinkage in Time-Dependent Deflection. Creep and shrinkage are expressed in terms of strain. At time $t$, the total strain $\varepsilon(t)$ of an uncracked concrete specimen under uniaxial loading has several components including elastic strain $\varepsilon_{\mathrm{e}}$, creep strain $\varepsilon_{\text {cr }}$, and shrinkage strain $\varepsilon_{\text {sh }}$. It is usually assumed (although not completely true) that the strains are independent of each other, so they can be calculated separately and then summed up together. Therefore, the concrete strain at aiven point and time $t$ can be written as follows [2]:

$$
\varepsilon(t)=\varepsilon_{\mathrm{e}}(t)+\varepsilon_{\mathrm{cr}}(t)+\varepsilon_{\mathrm{sh}}(t),
$$

where $\varepsilon_{\mathrm{e}}(t)$ is the instantaneous strain, $\varepsilon_{\mathrm{cr}}(t)$ represents the creep strain, and $\varepsilon_{\text {sh }}(t)$ shows the drying shrinkage strain. Creep strain is classified into two categories: linear and nonlinear ranges. At service level stresses in structures, which are less than about $0.4 f_{c}^{\prime}$, and in the absence of cracking, the creep strain depends on stress linearly; however, when the stress exceeds this level, nonlinear creep happens.

Previous studies have claimed that linear creep does not considerably affect shear and flexural strengths of shallow concrete beams [27]. As stated above, shallow and deep beams are different regarding strain distribution in the depths of their cross sections. Furthermore, the effects of strain distribution should be examined on the long-term behavior of RC deep beams. In the present study, the longterm behavior of deep beams in the serviceability limit state is first addressed using the accurate FEM approach through user subroutines UMAT and UEXPAN added to ABAQUS finite element software. Subroutine UMAT is associated with simulating the behavior of concrete under time-dependent factors (creep). Subroutine UEXPAN is a behavioral model of material under volume expansion or contraction used for simulation of shrinkage in concrete.

In linear creep theory, creep strain can be defined as follows [2]:

$$
\mathcal{E}_{\mathrm{cr}}(t)=\phi_{\text {linear }} \mathcal{E}_{\mathrm{e}}(t),
$$

where $\phi_{\text {linear }}$ is the creep coefficient, which is the ratio of the creep strain to the elastic strain at the start of loading.

When a concrete specimen is under a permanent stress exceeding $0.4 f_{c}^{\prime}$, nonlinear creep occurs [2]. Previous studies have indicated that the viscoelastic approach cannot be used for predicting the concrete behavior at high levels of stress, and it is necessary to make some corrections. Affinity hypothesis can be applied for generalizing linear creep to nonlinear creep from the serviceability point of view; it is 
used within the stress range of $0.4 f_{c}^{\prime}$ to $0.9 f_{c}^{\prime}$ [28]. In this hypothesis, the linear creep factor can be multiplied by a coefficient to consider the effects of nonlinear creep on displacements of beams. This hypothesis assumes that the linear and nonlinear creep strains are related through the actual stress ratio of $\eta$ within the stress range of $0.4 f_{c}^{\prime}$ to $0.7 f_{\mathrm{c}}^{\prime}$. The proportional coefficient can be estimated by the following equation [28]:

$$
\eta=1+2 \times\left(\frac{\sigma_{\mathrm{c}}}{f_{\mathrm{c}}^{\prime}}\right)^{4} .
$$

Previous research has suggested that the coefficient could be properly utilized for nonlinear creep problems [28]. The proportional coefficient proposed by Bažant and Kim [29] can be applied in the stress range exceeding $0.7 f_{c}^{\prime}$, as defined in the following equation:

$$
\eta=\frac{1+3 s^{5}}{1-\Omega},
$$

where $s=\sigma_{\mathrm{c}} / f_{\mathrm{c}}^{\prime}$ and $\Omega=s^{10}$. Parameter $\Omega$ models the failure effects of concrete at high-stress levels. In this study, considering the effects of nonlinear creep, displacements of deep beams can be obtained using the proportional coefficient and outcome of subroutine UMAT for linear creep.

\subsection{Rate-of-Creep Method and Volume Expansion to Consider} Linear/Nonlinear Creep and Shrinkage. Under constant environmental factors, stress is expressed by a compliance function $J\left(t, t^{\prime}\right)$ defined as the strain $\varepsilon$ at time $t$ caused by a unit uniaxial stress applied at time $t^{\prime}$. The relationship between stress and strain in concrete can be expressed using the Kelvin chain model. The model includes a number of Kelvin units called $\mu$. Each Kelvin unit includes a spring with a hardness of $E_{\mu}(t)$ parallel to a damper with the viscosity of $\eta_{\mu}(t)=E_{\mu}(t) \tau_{\mu}(t)$. Note that parameter $\tau_{\mu}$ is known as retardation time [30]. In the step by step analysis, the values of $E_{\mu}(t)$ and $\eta_{\mu}(t)$ can be assumed constant in each time interval whose proportional magnitude would be adopted in the next step. The outline of the computer program consisting of implementation of rate-of-creep (UMAT) and shrinkage method (UEXPAN) in ABAQUS is provided in Algorithm 1 [30].

\section{Uncertainty Modeling of Shrinkage and Creep}

Different material models can be considered in analysis for estimating creep and shrinkage effects on concrete structures including ACI209-08 [31], CEB-FIP90 [32], the Japan Society of Civil Engineers (JSCE) [33], the Gardner and Lockman (GL2000) [34], and B3 [35]. The most frequently used model in codes is the one suggested by ACI Committee 209. In this code, the shrinkage strain may be calculated using the following equation [31]:

$$
\varepsilon_{\mathrm{sh}}\left(t, t^{\prime}\right)=\Psi_{1} \frac{\left(t-t^{\prime}\right)}{f+\left(t-t^{\prime}\right)} \varepsilon_{\mathrm{u}}^{*},
$$

where $\varepsilon_{\mathrm{sh}}\left(t, t^{\prime}\right)$ is the shrinkage strain at time $t$ (age of concrete); $\varepsilon_{\mathrm{u}}^{*}$ denotes the ultimate shrinkage strain (at the time of infinity) which depends on experimental results, while coefficient $f$ depends on the curing condition; $t^{\prime}$ is the age of concrete at start of drying; $\Psi_{1}$ shows the uncertainty factor of the shrinkage model. Indeed, creep coefficient may be written as follows [31]:

$$
\phi\left(t, t^{\prime}\right)=\Psi_{2} \frac{\left(t-t^{\prime}\right)^{0.6}}{10+\left(t-t^{\prime}\right)^{0.6}} \phi_{\mathrm{u}},
$$

where $\phi\left(t, t^{\prime}\right)$ is the creep coefficient at time $t$ (age of concrete), $\phi_{\mathrm{u}}$ represents the ultimate creep coefficient (at the time of infinity) which depends on experimental results, $t$ is the observation (current) time (days), and $\Psi_{2}$ is the uncertainty factor of the creep model. For standard conditions and at ambient relative humidity of $40 \%$, the average value suggested by the ACI-209 standard for the ultimate shrinkage strain $\varepsilon_{\text {shu }}$ is $780 \times 10^{-6} \mathrm{~mm} / \mathrm{mm}$. In the absence of specific data, the average value recommended for $\phi_{\mathrm{u}}$ is calculated using the following equation [31]:

$$
\phi_{\mathrm{u}}=2.35 \gamma_{\mathrm{c}},
$$

where $\gamma_{c}$ is an empirical factor.

In this study, coefficients of variations of shrinkage and creep properties are set to $54.2 \%$ and $51.7 \%$, respectively, based on the previous studies $[35,36]$.

\section{Deep Beams' Description and FE Modeling}

ABAQUS suggests several models to simulate the nonlinear behavior of concrete. The concrete damaged plasticity (CDP) model is different from others in that it is able to separately simulate compressive and tensile behaviors of concrete and introduce reduction of elastic modulus. In addition to static loads, the model is also capable of modeling cyclic loads. Note that the behavioral model uses Drucker-Prager failure criteria with Lubliner et al.'s yield function [37]. For the serviceability limit state, subroutines UMAT and UEXPAN are used, while for the strength limit state, the CDP model along with a proposed method, here called the "fixed volume contraction scheme," type of simulating shrinkage, is employed to evaluate the probability of failure in each target age.

Due to lack of experimental data related to creep and shrinkage of deep concrete beams, for gathering train and test data, required for time-dependent reliability analysis, the finite element simulation method was used. In the beginning, the software was initially examined using the experimental results for long-term deflection of shallow concrete beams by Gilbert [38]. Then, the results of the software were compared with the final strength of deep concrete beams determined in the laboratory work by Salamy et al. [39]. According to the two-step verifications, it was concluded that the software could manage to properly model deep concrete beams and capture the effects of creep and shrinkage. In the Gilbert's test [38], 6 conventional concrete beams with different geometries and loading conditions 
Start

UEXPAN subroutine

(i) Assign dimension for parameters used in the UEXPAN subroutine

(ii) Evaluate initial parameters using the ACI formula for the shrinkage effect $\left(\varepsilon_{\mathrm{sh}}\left(t, t_{\mathrm{c}}\right)=\left(\left(t-t_{\mathrm{c}}\right)^{\alpha} / f+\left(t-t_{\mathrm{c}}\right)^{\alpha}\right) \varepsilon_{\text {shu }}\right)$

(iii) Calculate shrinkage strain in each time step

UMAT subroutine

(i) Assign initial parameters for the creep effect based on the ACI code

(ii) Select retardation times $\tau_{\mu}=10^{-7+\mu}$

(iii) Calculate the discretized spectrum based on Widder's formula $2.35 \gamma_{\mathrm{c}} \times \psi(\xi)$

(iv) Assign exponential algorithm parameters $\beta_{\mu}, \lambda_{\mu}$, and $D_{\mu}$ to the program

(v) Calculate the effective modulus $E_{t_{n}-1 / 2}^{\prime \prime}=\left[E_{0}^{-1}+\sum_{\mu=1}^{N} D_{\mu}^{-1}\right]^{-1}$

(vi) Compute the inelastic creep strain increment $\Delta \varepsilon^{\prime \prime}=\sum_{\mu=1}^{N}\left(1-\beta_{\mu}\right) \gamma_{\mu}^{(n-1)}$

Run ABAQUS with stress-strain relation $\Delta \sigma=E^{\prime \prime} D\left(\Delta \varepsilon-\Delta \varepsilon^{\prime \prime}\right)$

(i) Update the internal variable vectors $\gamma_{\mu}^{(n)}=\lambda_{\mu} \Delta \sigma D_{\mu}^{-1}+\beta_{\mu} \gamma_{\mu}^{(n-1)}$

End loop over elements and integration points

End loop over time steps

underwent long-term loading. All specimens were simply supported beams with a span of $3.5 \mathrm{~m}$ under a constant load for 400 days. The applied force varied from $11.8 \mathrm{kN}$ to $27 \mathrm{kN}$. The analytical results obtained by implementing subroutines UMAT and UEXPAN were compared with the test results. The geometrical characteristics of the tested beams are presented in Table 1 and Figure 1.

As observed in Figure 2, the proposed finite element analytical model shows good accuracy concerning changes in reinforcement and loading on beams. The model does not indicate a notable deviation in the changes of parameters; this properly matches experimental results. As the creep model of ACI does not consider drying creep, analytical results show $1 \%$ to $6 \%$ deviation from laboratory results after 400 days of loading.

In the second stage of verification, the experimental work by Salamy et al. [39] is addressed. Six simply supported $\mathrm{RC}$ deep beams are selected and modeled with differences in loading, physical, and geometrical properties. The geometrical properties of these 6 beams are provided in Figure 3 and Table 2.

In the following, a bullet-point summary for RC deep beams modeling is shown:

(i) Geometry modeling using ABAQUS

(ii) Material modeling using the concrete damaged plasticity (CDP) model or UMAT and UEXPAN subroutines

(iii) Analysis of RC deep beams as well as the postprocessing procedure

(iv) Verification of results using experimental data

For concrete, the C3D8R element, which is a linear brick element for general purposes, is used, and for rebar, a 3D beam element, namely, B31, is used [40]. As can be seen in Table 3, there is an excellent consistency between the analytical and experimental results.
As a conclusion, the two-stage verifications can demonstrate capability of the analytical modelling to simulate time-effect deformation and predict strength of the RC deep beams.

\section{Definition of Input Variables}

The properties of the input variables assumed in this work are summarized as follows. Shrinkage and creep model uncertainty factors $\left(\Psi_{1}, \Psi_{2}\right)$ suggested by Bazant and Baweja [35], compressive strength of concrete $\left(f_{\mathrm{c}}^{\prime}\right)$ according to Yang [36], compression reinforcement ratio $\left(\rho_{1}\right)$, shear span-to-effective depth ratio $(a / d)$, age of concrete in the first loading $\left(t^{\prime}\right)$, and relative humidity $(h)$ are assumed to be random variables following a normal distribution [36]. It is also assumed that these input variables are independent of each other. Note that sensitivity analysis is conducted based on the two parameters of shear span-to-effective depth ratio $(a / d)$ and sustained load $(P)$. Creep and shrinkage parameters such as $\Psi_{1}, \Psi_{2}, f_{\mathrm{c}}^{\prime}, \rho_{1}, t^{\prime}$, and $h$ are randomly altered for each analysis based on Gaussian distribution fuzzy membership functions. The depth of beam changes incrementally from $0.25 \mathrm{~m}$ to $2.0 \mathrm{~m}$ with the same $(L)$ and sustained load $(P)$. The change of $a / d$ is applied with a rise in $d$ with a constant value of $a$. For each time of dependent reliability analysis, three load levels of $40 \%, 70 \%$, and $90 \%$ (for the strength limit state only) are chosen for the shear/ flexural strength. Table 4 summarizes the boundary range of input random variables for ANFIS modeling.

\section{Definition of the Limit State}

A structure must be designed to simultaneously satisfy both serviceability and strength requirements. Two limit states for serviceability and shear strength are considered in this study. The serviceability limit state is usually dealing with excessive static deflections that can cause 
TABLE 1: Geometry and properties of RC shallow beams [38].

\begin{tabular}{lcccccc}
\hline Beam & Rebar no. & Rebar diagram & As $\left(\mathrm{mm}^{2}\right)$ & Vertical cover Cb $(\mathrm{mm})$ & Horizontal cover Cs $(\mathrm{mm})$ & Distance between rebars $S(\mathrm{~mm})$ \\
\hline B1-a & 2 & 16 & 400 & 40 & 40 & 150 \\
B1-b & 2 & 16 & 400 & 40 & 40 & 150 \\
B2-a & 2 & 16 & 400 & 25 & 25 & 180 \\
B2-b & 2 & 16 & 400 & 25 & 25 & 180 \\
B3-a & 3 & 16 & 600 & 25 & 25 & 90 \\
B3-b & 3 & 16 & 600 & 25 & 25 & 90 \\
\hline
\end{tabular}
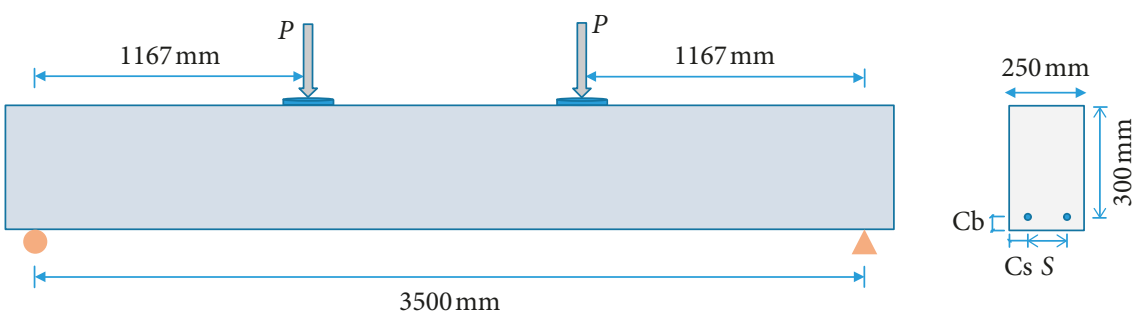

FIGURE 1: Geometry of the cross sections of beams.

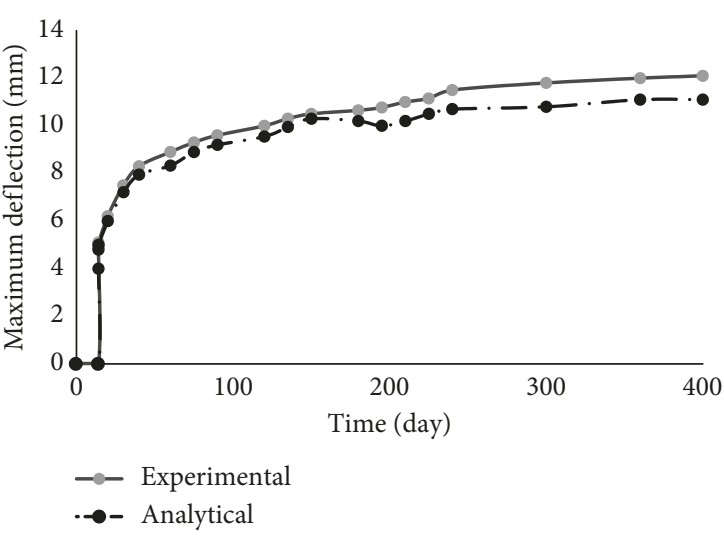

(a)

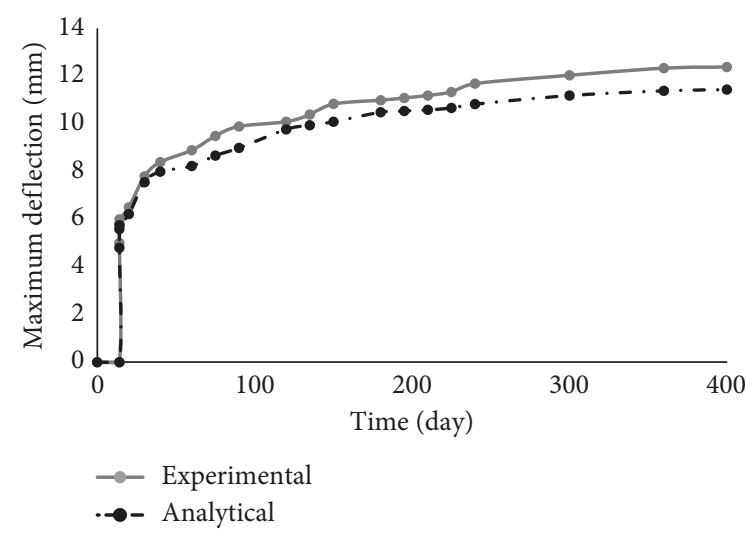

(b)

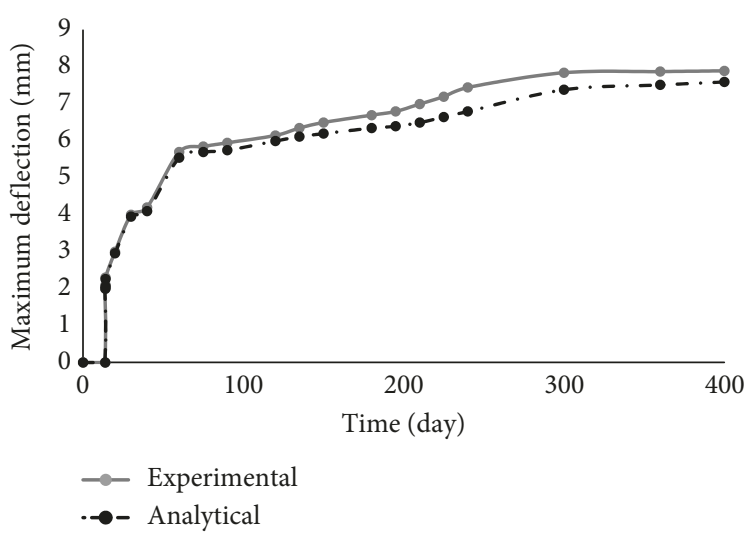

(c)

FIGURE 2: Variations of the maximum deflection with time in experimental and analytical analyses (experimental work by Gilbert [38]): (a) B1-a; (b) B2-a; (c) B3-b.

occurrence of visible cracks in concrete beams. In the serviceability limit state, maximum deflections of deep beams are compared to allowable beam deflection limits. Accordingly, the serviceability limit state function $G(x)$ can be written as follows:

$$
G(x)_{\text {SLS }}=\Delta_{\text {allowable }}-\Delta_{\max },
$$

where $\Delta_{\text {allowable }}$ is the allowable deflection limit and $\Delta_{\max }$ represents the maximum midspan deflection of deep concrete beams. 


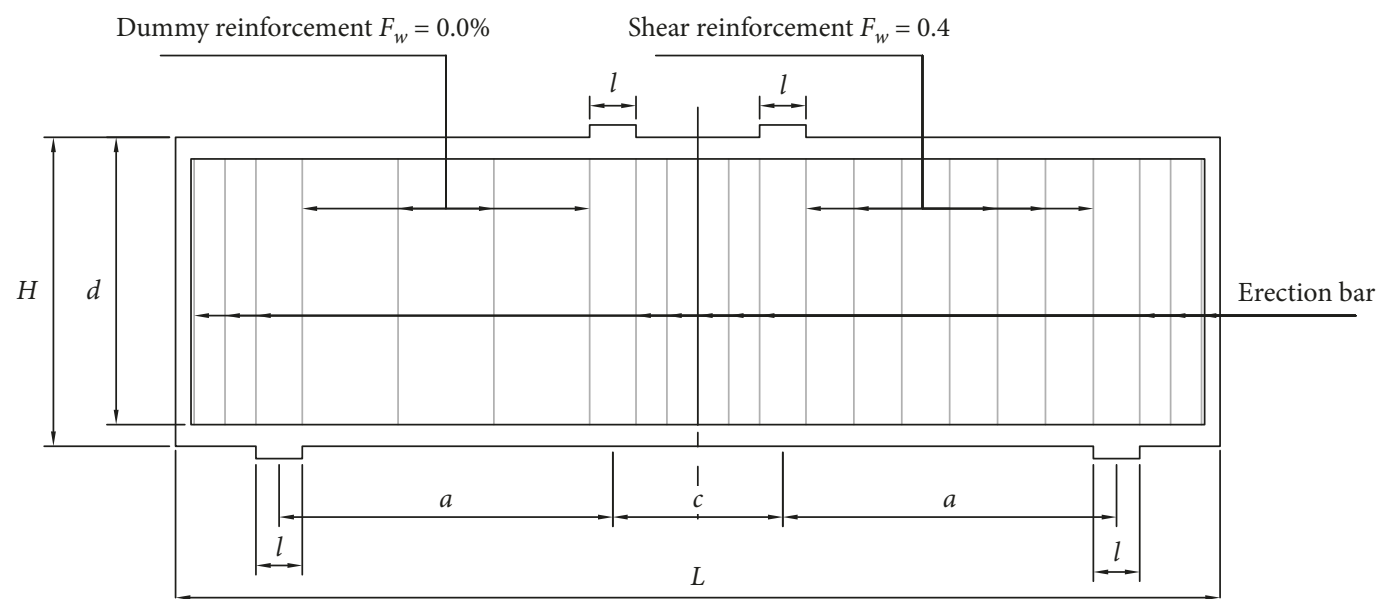

FIgURE 3: Schematic view of deep concrete beams [39].

TABLE 2: Geometry and properties of deep concrete beams.

\begin{tabular}{|c|c|c|c|c|c|c|c|c|c|}
\hline Beam & a/d & $\begin{array}{l}\text { Effective } \\
\text { depth } d \\
(\mathrm{~mm})\end{array}$ & $\begin{array}{l}\text { Beam's } \\
\text { length } L \\
(\mathrm{~mm})\end{array}$ & $\begin{array}{l}\text { Beam's } \\
\text { width } b \\
(\mathrm{~mm})\end{array}$ & $\begin{array}{l}\text { Bearing plate's } \\
\text { width } l \\
(\mathrm{~mm})\end{array}$ & $\begin{array}{c}\text { Shear } \\
\text { reinforcement } \\
A_{\mathrm{v}}(\text { ratio })\end{array}$ & $\begin{array}{l}\text { Flexural } \\
\text { reinforcement } \\
A_{\mathrm{s}}(\text { ratio })\end{array}$ & $\begin{array}{c}\text { Concrete } \\
\text { compressive strength } \\
f_{c}\left(\mathrm{~N} / \mathrm{mm}^{2}\right)\end{array}$ & $\begin{array}{l}\text { Rebar tensile } \\
\text { strength } \\
f_{\mathrm{y}}\left(\mathrm{N} / \mathrm{mm}^{2}\right)\end{array}$ \\
\hline B-4 & 0.5 & 400 & 1100 & 240 & 100 & 0.8 & 2.02 & 31.3 & 376 \\
\hline B-7 & 1 & 400 & 1500 & 240 & 100 & 0.4 & 2.02 & 31.3 & 376 \\
\hline B-10R & 1.5 & 400 & 1500 & 360 & 150 & 0 & 2.02 & 23 & 388 \\
\hline B-14 & 1.5 & 1000 & 4750 & 600 & 250 & 0 & 1.99 & 31 & 398 \\
\hline B-16 & 1.5 & 1400 & 6650 & 840 & 350 & 0 & 2.05 & 27.3 & 394 \\
\hline B-18 & 1.5 & 1400 & 6650 & 840 & 350 & 0.4 & 2.05 & 31.3 & 397.5 \\
\hline
\end{tabular}

TABle 3: Experimental and analytical results for deep concrete beams.

\begin{tabular}{lcccc}
\hline Beam & $\begin{array}{c}\text { Experimental ultimate } \\
\text { strength }(\mathrm{kN})\end{array}$ & $\begin{array}{c}\text { Analytical ultimate } \\
\text { strength }(\mathrm{kN})\end{array}$ & $\begin{array}{c}\text { Experimental maximum midspan } \\
\text { deflection }(\mathrm{kN})\end{array}$ & $\begin{array}{c}\text { Analytical maximum midspan } \\
\text { deflection }(\mathrm{kN})\end{array}$ \\
\hline B-7 & 1181 & 1144 & 2.8 & 2.93 \\
B-14 & 3969 & 3850 & 9.6 & 9.3 \\
B-16 & 5975 & 5880 & 10.49 & 10.74 \\
\hline
\end{tabular}

TABLE 4: Boundary range of input parameters.

\begin{tabular}{lcccc}
\hline Inputs & \multicolumn{3}{c}{ Range } & Sources \\
\hline Creep model uncertainty & & Minimum & Maximum & Reference [35, 36] \\
Shrinkage model uncertainty & $\Psi_{1}$ & 0.5 & 1.5 & Reference [35, 36] \\
Compressive strength (MPa) & $\Psi_{2}$ & 0.5 & 1.5 & Observed and Reference [36] \\
Compression reinforcement ratio & $f_{\mathrm{c}}^{\prime}$ & 30 & 50 & Observed \\
Shear span-to-effective depth ratio & $\rho_{1}$ & 0.009 & 0.02 & Observed and Reference [41] \\
Age of concrete at the first loading (day) & $a / d$ & 0.5 & 5.8 & Observed and Reference [31] \\
Relative humidity & $t^{\prime}$ & 3 & 0.9 & Observed and Reference [36] \\
\hline
\end{tabular}

The deflection limit in equation (8), which takes into account creep and shrinkage effects, is usually unclear. Unlike for shallow beams, in design codes, there is no explicitly prescribed deflection limit for the effect of long-term loading on RC deep beams. Thus, midspan deflection limits for shallow beams such as $L / 240$ and $L / 360$ can be considered along with two stricter limitations of $L / 500$ and $L / 600$ for sensitive structures, where $L$ is the beam span $[17,41]$.
In the ultimate strength reliability assessment, the probability of shear failure of deep concrete beams (in the case of shallow beams, flexural failure can be conceived) in their lifetime is addressed. In order to assess failure probability, it is necessary to know the margin between two random variables of resistances $R$ and applied load $S$. Thus, the ultimate limit state function can be expressed as follows: 


$$
G(x)_{\mathrm{ULS}}=R-S .
$$

where in general, $R$ and $S$ are considered as time-independent output variables.

The sign function $G(x)$ describes the state of structure. For positive value of $G(x)$, the state of structure is safe; $G(x)<0$ defines the domain of failure events; and $G(x)=0$ conventionally defines the limit state surface, i.e., the boundary between the two mentioned domains.

\section{Architecture of ANFIS Modeling}

ANFIS (adaptive neuro-fuzzy inference system) is a wellknown artificial neural network based on a fuzzy concept for modeling complex systems. ANFIS represents SugenoTsukamoto fuzzy models in which a hybrid learning algorithm is used. ANFIS was first proposed by Jang [42]. ANFIS is a type of artificial neural network that combines the advantages of both fuzzy inference and ANN (artificial neural network) methods. Advantages of ANN can be categorized as follows [43]:

(i) Using a self-learning process for finding a reliable solution

(ii) A simplified algorithm without any complex mathematical formulation

(iii) Ability to solve moderate complex nonlinear problems

(iv) Robustness of algorithm in processing structural analysis

Despite its merit, some disadvantages of this method can be highlighted as follows:

(i) Training process significantly impacts the computational cost

(ii) Effect of the ambiguity of information is not considered in this method

Some advantages of ANFIS compared to ANN can be introduced as follows [44]:

(i) Combination of powerful mathematical concept of the artificial neural network and human knowledgebased fuzzy logic system. This provides a robust framework for solving complicated problems.

(ii) The ability to simulate fully nonlinear complex systems.

(iii) Rapid learning and reducing computational costs.

Therefore, according to the mentioned points, ANFIS is used for predicting long-term deflection of RC deep beams.

In the following, a bullet-form ANFIS architecture designed for 7 input variables (depicted in Table 4) using the Gaussian membership function is shown:

(i) Selecting the proper input data

(ii) Fuzzification step: assigning the membership function (iii) Implication of rules for the establishing the fuzzy network

(iv) Normalization and weighted outputs

(v) Defuzzification as well as aggregation

(vi) Output layer including midspan deflection or shear strength of RC deep beams

In ANFIS, a hybrid method (a hybrid algorithm adjusts the resultant parameters in a forward pass and the premise parameters in a backward pass) and gradient descent scheme along with the least-squares method aim to minimize the data error.

\section{Verification of ANFIS}

The ANFIS model developed in this research is first trained by 100 input-output datasets and further tested by 25 datasets. Due to the large number of input parameters and despite the satisfactory results in the first stage, for final training of the network, 280 input-output datasets are used. The 100 trained data for estimating the deflection of RC deep beams are reported in Table 5 .

To enhance the accuracy of the ANFIS model, a wide range of input parameters are selected and applied to the model. These datasets are created through FEM analyses, which have been verified by experimental results. After testing different learning algorithms with 480 different epochs, the model reaches the minimum error size (Figure 4). On the contrary, the maximum convergence in the model is reached after 1800 epochs. To evaluate the adequacy of the model developed in ANFIS, three norms are used. These norms are root-mean-square error (RMSE), mean squared error (MSE), and mean absolute deviation (MAD) [45, 46].

Figure 4 depicts the training process of the developed ANFIS model to establish the fuzzy relationship between input and output variables, including the maximum deflection of RC deep beams. ANFIS model minimizes the error by increasing epoch's number to stabilize the network.

In addition, Table 6 lists the results of sensitivity analysis of ANFIS at the serviceability level for the training step based on root-mean-square error (RMSE), mean squared error (MSE), and mean absolute deviation (MAD).

Figure 5 demonstrates a good consistency between target and output data, confirming the efficiency of the ANFIS model.

In the case of the strength limit state, the performance of the model is evaluated using two different error functions. The root-mean-square error (RMSE) and mean absolute percentage error (MAPE) [46], for the strength limit state of RC deep beams, are represented in Table 7.

As presented in Figure 5 and Tables 6 and 7, it can be concluded that the ANFIS model is capable enough to predict deflection and shear strength of RC deep beams. Comparison of figures and errors suggests that subclustering the ANFIS model along with the hybrid optimization approach has been close to FEM and a few experimental results. Figure 6 shows the sample results of training data in time-dependent ANFIS models for minimizing the error size 
TABLE 5: Train data used in ANFIS for the load level of $40 \%$ of the beam strength (100 input-output datasets).

\begin{tabular}{|c|c|c|c|c|c|c|c|c|}
\hline$\Psi_{1}$ & $\Psi_{2}$ & $f_{\mathrm{c}}^{\prime}(\mathrm{MPa})$ & $\rho_{1}$ & $a / d$ & $t^{\prime}$ & $h$ & $L(\mathrm{~mm})$ & $\Delta_{\max }(\mathrm{mm})$ \\
\hline 1 & 1 & 30 & 0.012 & 1.1 & 7 & 0.6 & 3000 & 2.41 \\
\hline 0.8 & 0.8 & 30 & 0.012 & 1.1 & 7 & 0.6 & 3000 & 2.12 \\
\hline 0.7 & 0.7 & 30 & 0.012 & 1.1 & 7 & 0.6 & 3000 & 2.01 \\
\hline 1 & 1 & 40 & 0.012 & 1.1 & 7 & 0.6 & 3000 & 2.32 \\
\hline 1 & 1 & 50 & 0.012 & 1.1 & 7 & 0.6 & 3000 & 1.95 \\
\hline 1 & 1 & 30 & 0.012 & 0.8 & 7 & 0.6 & 3000 & 2.04 \\
\hline 1 & 1 & 30 & 0.012 & 0.7 & 7 & 0.6 & 3000 & 1.96 \\
\hline 1 & 1 & 30 & 0.012 & 0.6 & 7 & 0.6 & 3000 & 1.84 \\
\hline 1 & 1 & 30 & 0.012 & 0.5 & 7 & 0.6 & 3000 & 1.78 \\
\hline 1 & 1 & 30 & 0.012 & 1.2 & 7 & 0.6 & 3000 & 2.52 \\
\hline 1 & 1 & 30 & 0.012 & 1.45 & 7 & 0.6 & 3000 & 3.08 \\
\hline 1 & 1 & 30 & 0.012 & 1.7 & 7 & 0.6 & 3000 & 4.43 \\
\hline 1 & 1 & 30 & 0.012 & 2 & 7 & 0.6 & 3000 & 4.97 \\
\hline 1 & 1 & 30 & 0.012 & 2.2 & 7 & 0.6 & 3000 & 5.66 \\
\hline 1 & 1 & 30 & 0.012 & 2.4 & 7 & 0.6 & 3000 & 6.13 \\
\hline 1 & 1 & 30 & 0.012 & 2.5 & 7 & 0.6 & 3000 & 6.43 \\
\hline 1 & 1 & 30 & 0.013 & 1.1 & 7 & 0.6 & 3000 & 2.4 \\
\hline 1 & 1 & 45 & 0.015 & 1.1 & 7 & 0.6 & 3000 & 2.38 \\
\hline 1 & 1 & 40 & 0.017 & 1.1 & 7 & 0.6 & 3000 & 2.35 \\
\hline 1 & 1 & 50 & 0.018 & 1.1 & 7 & 0.6 & 3000 & 2.32 \\
\hline 1 & 1 & 40 & 0.02 & 1.1 & 7 & 0.6 & 3000 & 2.3 \\
\hline 1.2 & 1.3 & 30 & 0.012 & 1.1 & 7 & 0.6 & 3000 & 3.65 \\
\hline 1 & 1 & 30 & 0.012 & 1.1 & 14 & 0.6 & 3000 & 2.34 \\
\hline 1 & 1 & 30 & 0.012 & 1.1 & 21 & 0.6 & 3000 & 2.11 \\
\hline 1 & 1 & 30 & 0.012 & 1.1 & 28 & 0.6 & 3000 & 2.02 \\
\hline 1 & 1 & 30 & 0.012 & 1.1 & 35 & 0.6 & 3000 & 1.96 \\
\hline 1 & 1 & 30 & 0.012 & 1.1 & 42 & 0.6 & 3000 & 1.91 \\
\hline 1 & 1 & 30 & 0.012 & 1.1 & 49 & 0.6 & 3000 & 1.86 \\
\hline 1 & 1 & 30 & 0.012 & 1.1 & 56 & 0.6 & 3000 & 1.84 \\
\hline 1 & 1 & 30 & 0.012 & 1.1 & 7 & 0.3 & 3000 & 4.98 \\
\hline 1 & 1 & 30 & 0.012 & 1.1 & 7 & 0.4 & 3000 & 4.11 \\
\hline 1 & 1 & 30 & 0.012 & 1.1 & 7 & 0.5 & 3000 & 3.34 \\
\hline 1 & 1 & 30 & 0.012 & 1.1 & 7 & 0.7 & 3000 & 2.03 \\
\hline 1 & 1 & 30 & 0.012 & 1.1 & 7 & 0.8 & 3000 & 1.87 \\
\hline 1 & 1 & 30 & 0.012 & 1.1 & 7 & 0.9 & 3000 & 1.76 \\
\hline 1 & 1 & 30 & 0.012 & 1.1 & 7 & 0.6 & 4000 & 3.6 \\
\hline 1 & 1 & 30 & 0.012 & 1.1 & 7 & 0.6 & 5000 & 5.94 \\
\hline 1 & 1 & 30 & 0.012 & 1.1 & 7 & 0.6 & 6000 & 9.12 \\
\hline 1 & 1 & 35 & 0.012 & 1.1 & 14 & 0.6 & 7000 & 10.14 \\
\hline 1 & 1 & 30 & 0.012 & 1.1 & 7 & 0.6 & 8000 & 17.77 \\
\hline 1 & 1 & 30 & 0.012 & 1.1 & 7 & 0.4 & 8000 & 19.37 \\
\hline 1 & 1 & 50 & 0.018 & 1.1 & 49 & 0.4 & 8000 & 15.88 \\
\hline 1 & 1 & 40 & 0.012 & 1.1 & 7 & 0.6 & 8000 & 18.31 \\
\hline 0.5 & 0.5 & 30 & 0.012 & 1.1 & 7 & 0.6 & 8000 & 12.66 \\
\hline 1 & 1 & 30 & 0.012 & 1.1 & 21 & 0.6 & 8000 & 17.39 \\
\hline 1 & 1 & 30 & 0.012 & 1.1 & 14 & 0.6 & 8000 & 16.98 \\
\hline 1 & 1 & 30 & 0.012 & 1.1 & 3 & 0.6 & 8000 & 22.14 \\
\hline 1 & 1 & 30 & 0.02 & 1.1 & 7 & 0.6 & 3000 & 2.38 \\
\hline 1 & 1 & 30 & 0.025 & 1.1 & 7 & 0.6 & 3000 & 2.35 \\
\hline 1 & 1 & 30 & 0.005 & 1.1 & 7 & 0.6 & 3000 & 2.43 \\
\hline 1 & 1 & 30 & 0.006 & 1.1 & 7 & 0.6 & 3000 & 2.43 \\
\hline 1 & 1 & 30 & 0.009 & 1.1 & 7 & 0.6 & 3000 & 2.42 \\
\hline 1 & 1 & 30 & 0.012 & 1.1 & 7 & 0.6 & 7000 & 12.58 \\
\hline 1 & 1 & 30 & 0.012 & 1.1 & 7 & 0.4 & 7000 & 14.17 \\
\hline 1 & 1 & 50 & 0.018 & 1.1 & 49 & 0.4 & 7000 & 12.78 \\
\hline 1 & 1 & 40 & 0.012 & 1.1 & 7 & 0.6 & 7000 & 12.31 \\
\hline 0.5 & 0.5 & 30 & 0.012 & 1.1 & 7 & 0.6 & 7000 & 10.27 \\
\hline 1 & 1 & 30 & 0.012 & 1.1 & 21 & 0.6 & 7000 & 11.19 \\
\hline 1 & 1 & 30 & 0.012 & 1.1 & 14 & 0.6 & 7000 & 12.18 \\
\hline 1 & 1 & 30 & 0.012 & 1.1 & 3 & 0.6 & 7000 & 13.44 \\
\hline
\end{tabular}

TABle 5: Continued.

\begin{tabular}{ccccccccc}
\hline$\Psi_{1}$ & $\Psi_{2}$ & $f_{\mathrm{c}}^{\prime}(\mathrm{MPa})$ & $\rho_{1}$ & $a / d$ & $t^{\prime}$ & $h$ & $L(\mathrm{~mm})$ & $\Delta_{\max }(\mathrm{mm})$ \\
\hline 1.2 & 1.35 & 30 & 0.012 & 1.1 & 7 & 0.6 & 7000 & 15.02 \\
0.4 & 0.4 & 30 & 0.012 & 1.1 & 7 & 0.6 & 7000 & 8.21 \\
0.8 & 0.4 & 30 & 0.012 & 1.1 & 7 & 0.6 & 7000 & 9.48 \\
0.9 & 0.9 & 30 & 0.018 & 1.1 & 7 & 0.6 & 7000 & 11.11 \\
1.1 & 1.1 & 30 & 0.012 & 1.1 & 7 & 0.6 & 7000 & 13.49 \\
1.4 & 1.2 & 30 & 0.012 & 1.1 & 7 & 0.6 & 7000 & 15.01 \\
1 & 1 & 30 & 0.01 & 1.1 & 7 & 0.6 & 5000 & 5.98 \\
1 & 1 & 30 & 0.018 & 1.1 & 7 & 0.6 & 5000 & 5.91 \\
1 & 1 & 30 & 0.02 & 1.1 & 7 & 0.6 & 5000 & 5.85 \\
1 & 1 & 30 & 0.03 & 1.1 & 7 & 0.6 & 5000 & 5.63 \\
1 & 1 & 30 & 0.002 & 1.1 & 7 & 0.6 & 5000 & 6.11 \\
1 & 1 & 30 & 0.003 & 1.1 & 7 & 0.6 & 5000 & 6.08 \\
1 & 1 & 30 & 0.005 & 1.1 & 7 & 0.6 & 5000 & 6.05 \\
1 & 1 & 30 & 0.006 & 1.1 & 7 & 0.6 & 5000 & 6.05 \\
1 & 1 & 30 & 0.007 & 1.1 & 7 & 0.6 & 5000 & 6.03 \\
1 & 1 & 30 & 0.012 & 5 & 7 & 0.6 & 6000 & 68.24 \\
1 & 1 & 30 & 0.012 & 4.8 & 7 & 0.6 & 6000 & 51.05 \\
1 & 1 & 30 & 0.012 & 4.3 & 7 & 0.6 & 6000 & 46.37 \\
1 & 1 & 30 & 0.012 & 4 & 7 & 0.6 & 6000 & 39.98 \\
1 & 1 & 30 & 0.012 & 3.5 & 7 & 0.6 & 6000 & 28.51 \\
1 & 1 & 30 & 0.012 & 3.2 & 7 & 0.6 & 6000 & 25.18 \\
1 & 1 & 30 & 0.012 & 3 & 7 & 0.6 & 6000 & 18.24 \\
1 & 1 & 30 & 0.012 & 2.7 & 7 & 0.6 & 6000 & 14.15 \\
1 & 1 & 30 & 0.012 & 2.5 & 7 & 0.6 & 6000 & 12.34 \\
1 & 1 & 30 & 0.012 & 5.3 & 7 & 0.6 & 6000 & 72.34 \\
1 & 1 & 30 & 0.012 & 5.8 & 7 & 0.6 & 6000 & 80.47 \\
1 & 1 & 30 & 0.012 & 4.5 & 7 & 0.6 & 6000 & 48.92 \\
1 & 1 & 30 & 0.012 & 1.1 & 21 & 0.6 & 5000 & 5.56 \\
1 & 1 & 30 & 0.012 & 1.1 & 28 & 0.6 & 5000 & 5.13 \\
1 & 1 & 30 & 0.012 & 1.1 & 35 & 0.6 & 5000 & 4.97 \\
1 & 1 & 30 & 0.012 & 1.1 & 42 & 0.6 & 5000 & 4.74 \\
1 & 1 & 30 & 0.012 & 1.1 & 49 & 0.6 & 5000 & 4.38 \\
1 & 1 & 30 & 0.012 & 1.1 & 56 & 0.6 & 5000 & 4.11 \\
1 & 1 & 30 & 0.012 & 1.1 & 3 & 0.6 & 5000 & 6.18 \\
\hline & & & & & & &
\end{tabular}

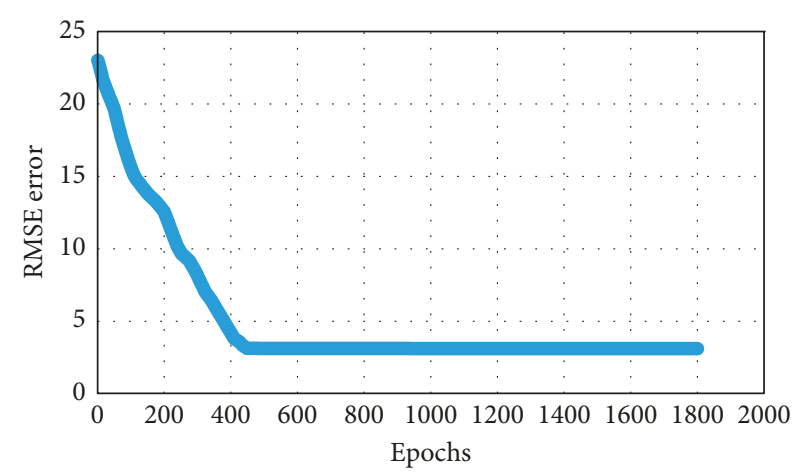

FIgURE 4: Training data process between input and target data based on the RMSE error for deflection of RC deep beams ( 280 input-output datasets).

by a proper number of epochs to stabilize sufficient ANFIS models.

\section{Monte Carlo Simulation}

When failure surface cannot be expressed analytically, the Monte Carlo Simulation (MCS) method is useful in 
TABle 6: RMSE, MSE, and MAD errors in the ANFIS network.

\begin{tabular}{lcccccc}
\hline \multirow{2}{*}{ Model } & RMSE & & \multicolumn{2}{c}{ MSE } & \multicolumn{2}{c}{ MAD } \\
& Train & & Test & Train & Test & Train \\
\hline ANFIS & 2.84 & & 3.88 & 7.77 & 14.32 & 1.64 \\
\hline
\end{tabular}

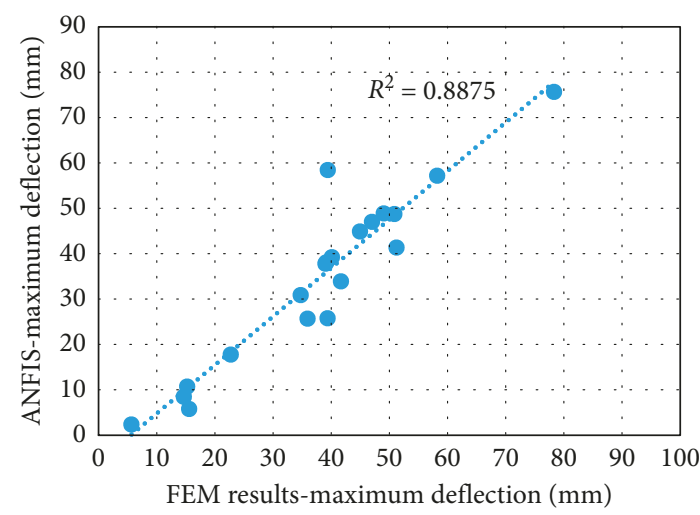

(a)

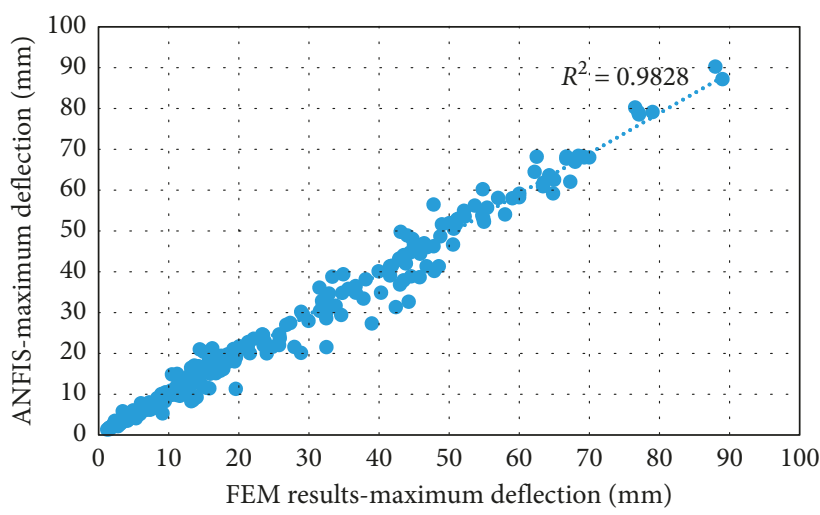

(b)

FIgURE 5: Relationship between the measurements (FEM results) and ANFIS predictions at (a) the test step of the ANFIS model and (b) the training step of the ANFIS model.

TABLE 7: RMSE and MAPE errors in the strength limit state.

\begin{tabular}{ccccccc}
\hline \multirow{2}{*}{ Model } & \multicolumn{2}{c}{ RMSE } & \multicolumn{2}{c}{ MAPE } & \multicolumn{2}{c}{$\mathrm{R}^{2}$} \\
& Train & Test & Train & Test & Train & Test \\
\hline ANFIS & 2.63 & 2.91 & 0.083 & 0.095 & 0.912 & 0.837 \\
\hline
\end{tabular}

reliability analysis. Problems subjected to complex geometry or complex phenomena such as creep and shrinkage with a large number of basic variables need an efficient approach including MCS. Unlike analytical methods such as firstorder reliability method (FORM) and second-order reliability method (SORM), which suffer correlations of variables and give approximate solutions to most practical problems with high numbers of input variables, MSC is able to yield more reliable solutions with adequate realizations [47].

Note that the ANFIS model is developed and MCS is adopted for each target age. Therefore, to estimate the probability of failure of concrete beams for each point, a massive calculation is required. In the following, a bulletpoint summary for time-dependent reliability analysis of RC beams is shown.

(i) Finite element modeling (FEM)

(ii) Train and test data gathering using FEM results

(iii) ANFIS network setup and gathering of all datasets

(iv) Monte Carlo Simulation (MCS) and probability of failure.

9.1. Serviceability Limit States. By performing structural reliability analysis at a certain age with four different allowable values of the midspan deflection of a beam with
$L=3.0 \mathrm{~m}$, the probability of RC deep beam failure at the serviceability limit state is estimated. In analyses, linear creep, nonlinear creep (which is dependent on the level of loading), and shrinkage effects in the serviceability limit state are addressed. For deflection limits of $L / 240, L / 360, L / 500$, and $L / 600$, the probability of failure in different ages of construction is assessed [17, 41]. As noted earlier, the probability of failure is first calculated for a constant length by changing $a / d$ from 0.5 to 4 . The corresponding curves are presented in Figure 7.

As observed in Figure 7, creep and shrinkage have less significant effects on deflection of RC deep beams. The shear behavior seems to play a dominant role in timedependent deflection of RC deep beams. For beams with $(a / d)=0.5$ and $(a / d)=4$ plus exceedance probability for $L / 600$ limitation at load level of $P=40 \%$, the beam strength is equal to 0.0332 and 0.183 , respectively. A fivefold increase can be observed for the shallow beam. Note that failure probability of 0.183 has occurred at $L / 600$ limitation, which is a rigorous limitation for beams. A sudden drop of failure probability in case of $(a / d)=3$ and $(a / d)=2$ is also observed. This decline can be interpreted as a margin between the two types of RC beams (i.e., deep and shallow). Shear-dominated behavior cannot occur for a/d values greater than 2, while flexural-dominated behavior can be seen for the ratios of $(a / d)=3$ and $(a / d)=2$. For the load level of $P=70 \%$ of the beam strength ratio, it is observed that nonlinear creep significantly affects the final deflection of RC beams. These results confirm that, in the nonlinear creep range, the affinity hypothesis theorem must be used for correct estimation of the long-term deflection of RC beams. As demonstrated in Figure 7(b), after 3 years, about $85 \%$ of the final failure probability is developed. After several years, under sustained load, the rate of change in $P_{\mathrm{f}}$ 


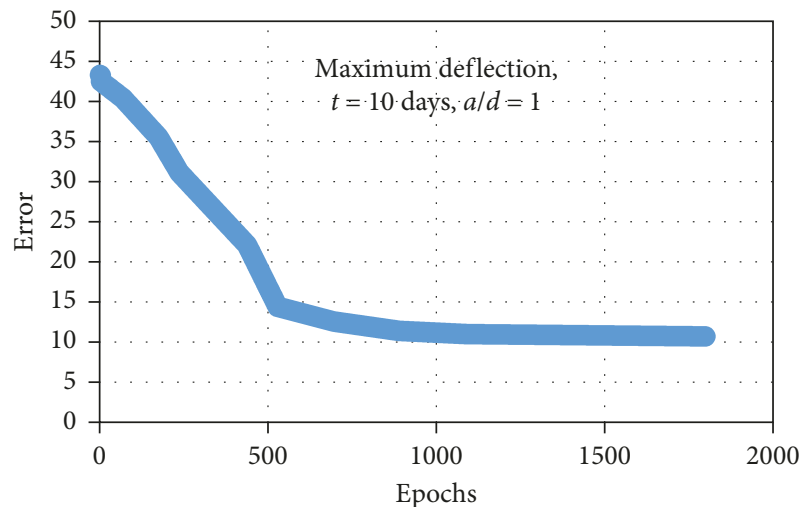

(a)

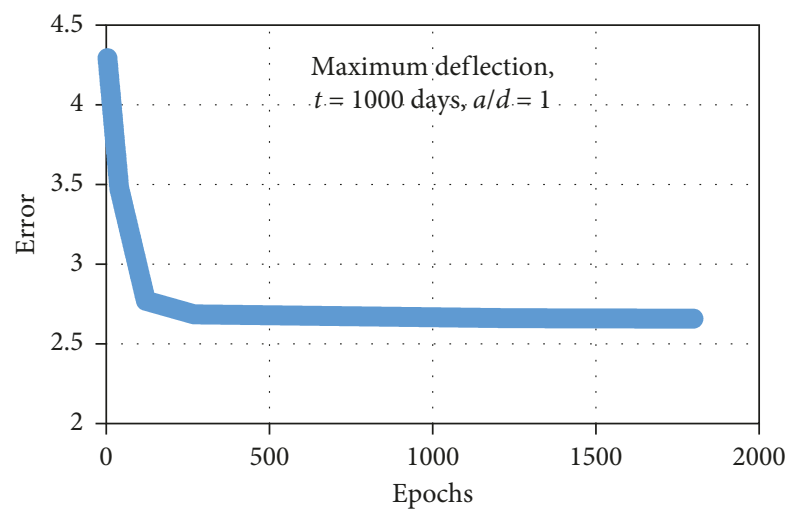

(c)

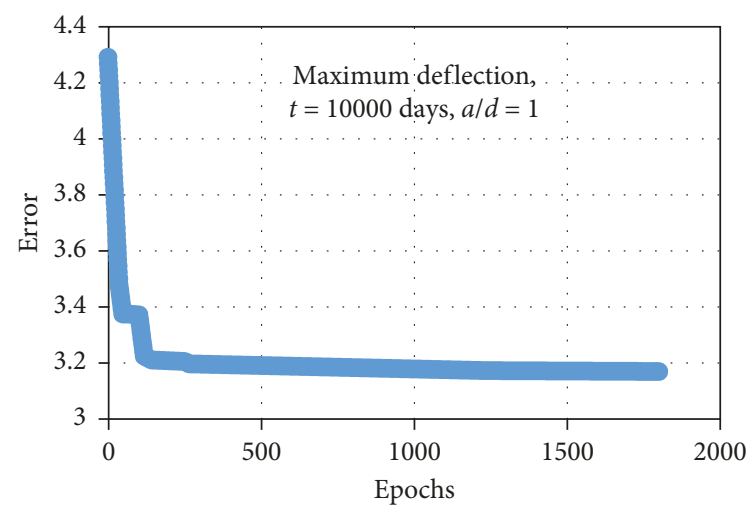

(e)

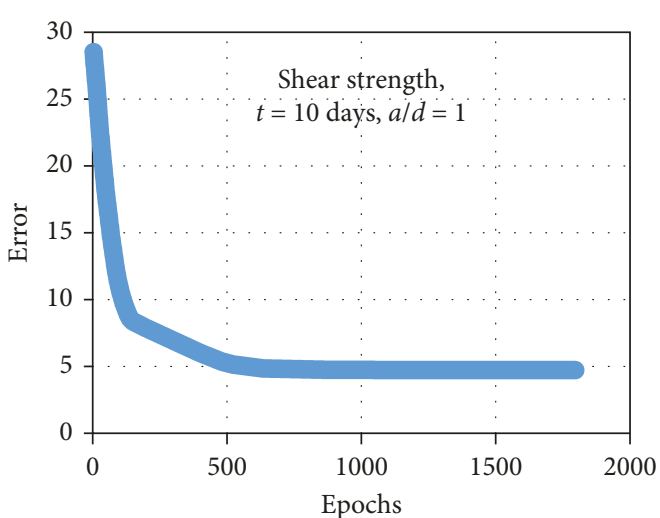

(b)

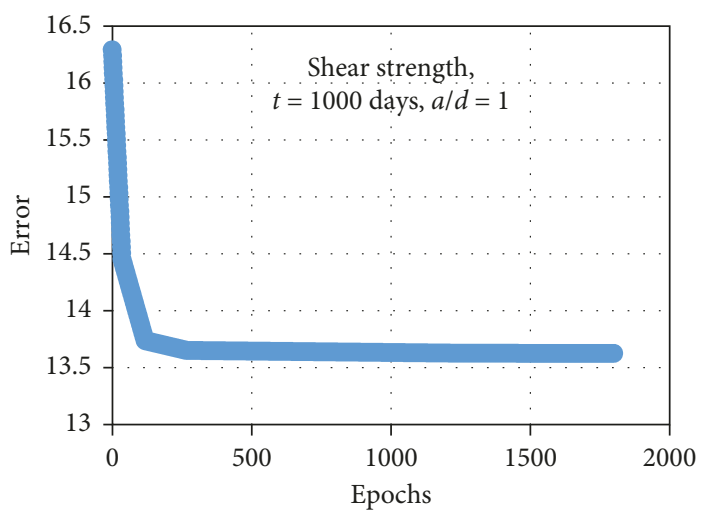

(d)

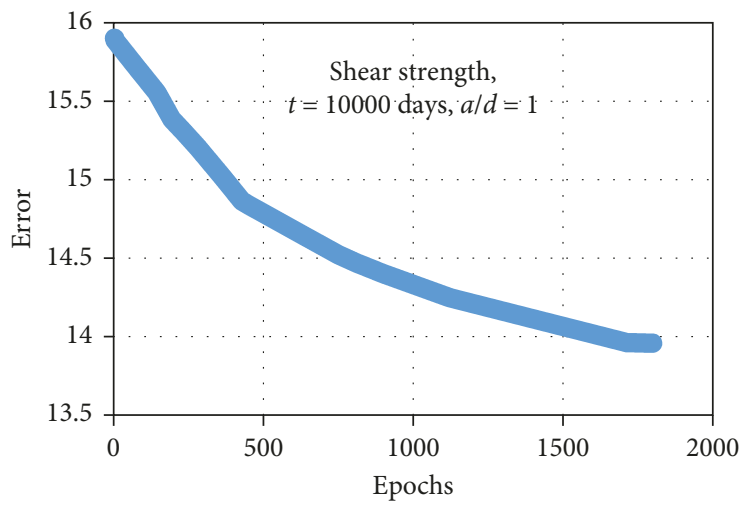

(f)

Figure 6: Process of stabilizing the ANFIS model by minimizing the error.

is very small. Design engineers and insurance companies can take this conclusion into account in their design and insurance premium calculation.

9.2. Strength Limit States. At a strength limit state level, the concrete damaged plasticity model is used to model RC deep beams where a constant volume reduction scheme, a kind of simulating shrinkage, is employed to model shrinkage and to adapt to the concrete model. Verification of this method was carried out by Hyodo et al. [48]. Three RC beams with effective depths of 250, 500, and $1000 \mathrm{~mm}$ have been selected and exposed to drying shrinkage. The geometry and properties of the beams are outlined in Tables 8 and $9 . b$ is the beam width; $h$ is the beam height; $L$ is the beam length; $c$ represents the distance between two loading points; $a$ shows the shear span; $d$ denotes the effective depth; $f_{c}$ refers to the compressive strength; $f_{\mathrm{t}}$ reflects the splitting tensile strength; $E_{\mathrm{c}}$ is Young's modulus.

The time-dependent shear strengths of the beams calculated based on the experimental test and the proposed model in this paper are shown in Table 10. For all beams, the proposed model predicts the shear strengths of RC beams accurately. At this step, the verification of software is completed.

In the first stage of the analyses, linear creep and shrinkage are applied to the FEM model to obtain test and 


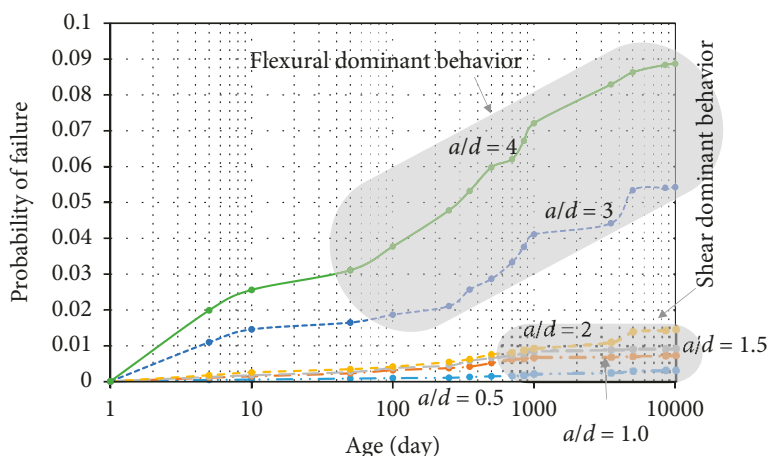

(a)

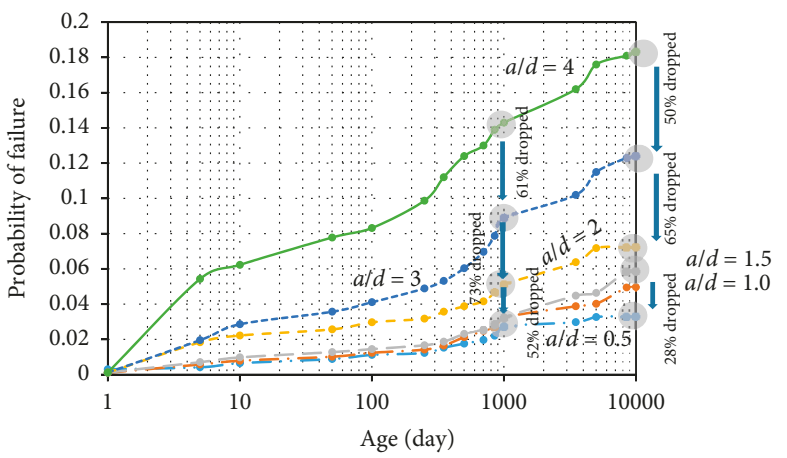

(c)

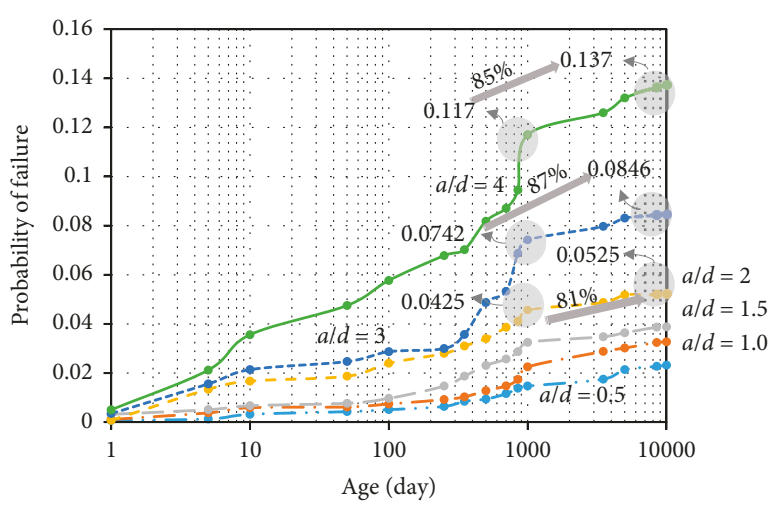

(b)

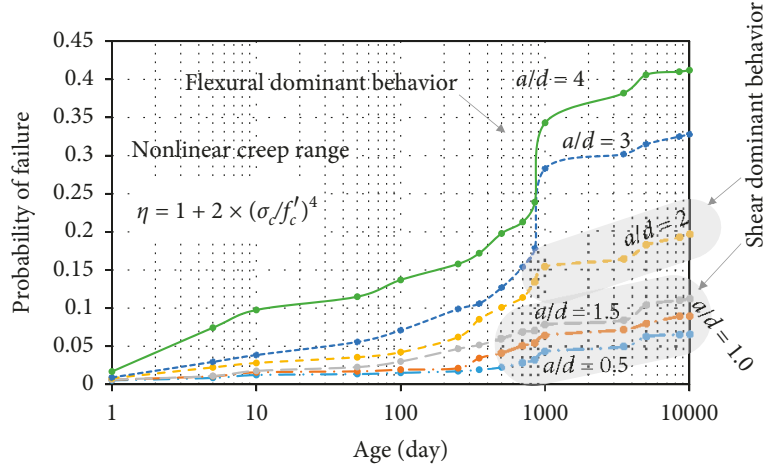

(d)

Figure 7: Exceedance probability of beam deflection at load levels of (a) $P=40 \%$ the beam strength and $L / 240$ limitation, (b) $P=40 \%$ the beam strength and $L / 500$ limitation, (c) $P=40 \%$ the beam strength and $L / 600$ limitation, and (d) $P=70 \%$ the beam strength and $L / 600$ limitation.

TABLE 8: Geometry of RC beams.

\begin{tabular}{lcccccc}
\hline Beam & $b(\mathrm{~mm})$ & $h(\mathrm{~mm})$ & $L(\mathrm{~mm})$ & $c(\mathrm{~mm})$ & $a(\mathrm{~mm})$ & $d(\mathrm{~mm})$ \\
\hline D250-A & 300 & 305 & 2300 & 200 & 750 & 250 \\
D500-A & 300 & 580 & 4500 & 500 & 1500 & 500 \\
D1000-A & 300 & 1130 & 7500 & 500 & 3000 & 1000 \\
\hline
\end{tabular}

TABLE 9: Properties of RC beams.

\begin{tabular}{lcccc}
\hline Beam & $\begin{array}{c}\text { Loading } \\
\text { age } \\
\text { (days) }\end{array}$ & $f_{\mathrm{c}}\left(\mathrm{N} / \mathrm{mm}^{2}\right)$ & $f_{\mathrm{t}}\left(\mathrm{N} / \mathrm{mm}^{2}\right)$ & $E_{\mathrm{c}}\left(\mathrm{kN} / \mathrm{mm}^{2}\right)$ \\
\hline D250-A & 125 & 40.1 & 3.2 & 21.5 \\
D500-A & 288 & 40.8 & 3.3 & 21.5 \\
D1000-A & 288 & 40.8 & 3.3 & 21.5 \\
\hline
\end{tabular}

train data for developing ANFIS. As mentioned earlier, the collapse probability of beams is first calculated with a constant length and altering a/d from 0.5 to 4 . Figure 8 reveals the relationship between collapse probability (shear or flexural failure) and type of the RC beam. It is clear that shrinkage and linear creep within the low-stress level range do not have any major effect on the collapse probability of RC beams.
TABLE 10: Outline of loading test results and the proposed model.

\begin{tabular}{lccc}
\hline Beam & $\begin{array}{c}\text { Experimental } \\
\text { shear } \\
\text { strength }(\mathrm{kN})\end{array}$ & $\begin{array}{c}\text { FEM shear } \\
\text { strength }(\mathrm{kN})\end{array}$ & $\begin{array}{c}\text { Percentage } \\
\text { changes }\end{array}$ \\
\hline D250-A & 79 & 81 & 2.5 \\
D500-A & 140 & 137 & 2.2 \\
D1000-A & 208 & 208 & 0 \\
\hline
\end{tabular}

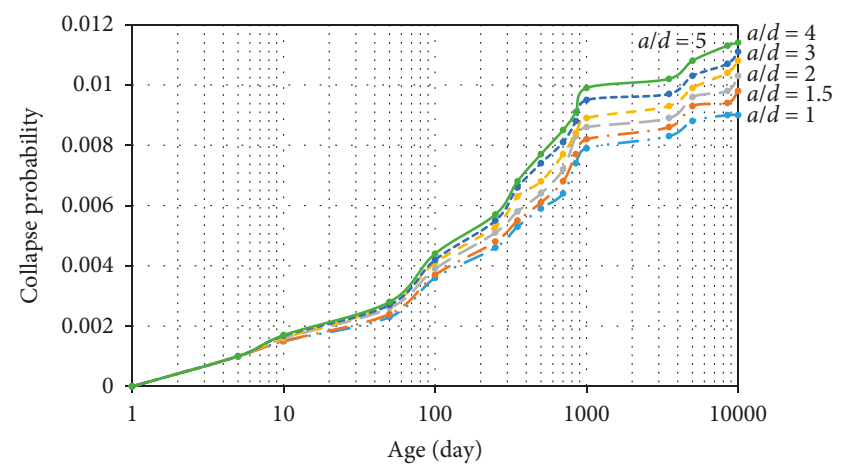

FIGURE 8: Collapse probability of failure in RC beams related to the strength limit state at the load level of $P=40 \%$ of the beam strength, $L=3 \mathrm{~m}$. 


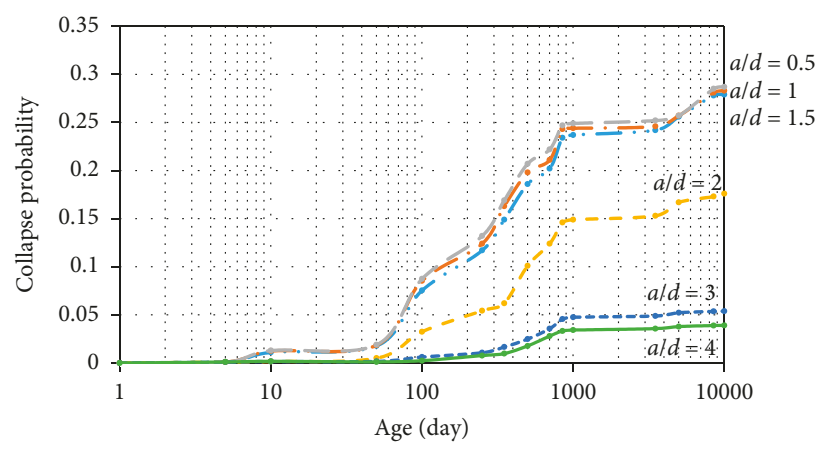

Figure 9: Collapse probability of RC beams in the strength limit state at the load level of $P=70 \%$ of the beam strength, $L=3 \mathrm{~m}$.

As shown in Figure 8, over time, the collapse probability will grow mildly. Previous research investigations have also demonstrated that linear creep does not considerably affect the shear and flexural strengths of shallow beams, confirming the results shown in Figure 8 [27]. For both types of beams, low values of collapse probability can be achieved, as observed in this figure. For instance, with linear creep and shrinkage assumption, for $(a / d)=4$, a maximum collapse probability of 0.0114 is obtained, which is very small and can be neglected by design engineers and insurance companies. Note that no tangible difference can be observed between the rates of collapse over time for RC deep and shallow beams.

In the second stage, the collapse probability for RC beams at the load level of $70 \%$ of the beam strength is investigated in the presence of creep and shrinkage effects. Figure 9 indicates the results for beams with different shear span-to-depth ratios subjected to the load level of $70 \%$ of the beam strength. It is noteworthy that, within this range of stress, the linear creep should be substituted by a nonlinear creep. Furthermore, a damage index considering stiffness degradation along with the creep damage model is employed here.

To this end, the following nonlinear damage index (equation (10)) recommended by Mazzotti and Savoia [49] is used (Figure 10):

$$
D=\left(\frac{\sigma}{f_{\mathrm{c}}^{\prime}}\right)\left[0.16+\frac{0.008}{1-\left(\left(\sigma / f_{\mathrm{c}}^{\prime}\right) / 0.9\right)}\right] .
$$

The computed collapse probability for both deep and shallow beams is revealed in Figure 10. As can be seen, the effect of shrinkage and nonlinear creep on the shear strength of RC deep beams is considerable. In the case of shallow beams, the shrinkage and nonlinear creep do not have prominent effect on flexural strength of shallow beams. If a volume reduction scheme without the nonlinear damage index is applied, $75 \%$ of the total collapse probability is achieved. It can be deduced that, at moderate sustained load levels, the greatest share of collapse probability belongs to the shrinkage. For instance, $P_{\mathrm{f}}$ in the case of deep beams is up to 5 times larger than that in shallow beams after 1000 days. As a conclusion, within the load level range of $70 \%$ of the beam strength, a safety factor of 1.25 is applicable to the shear design of RC deep beams considering shrinkage

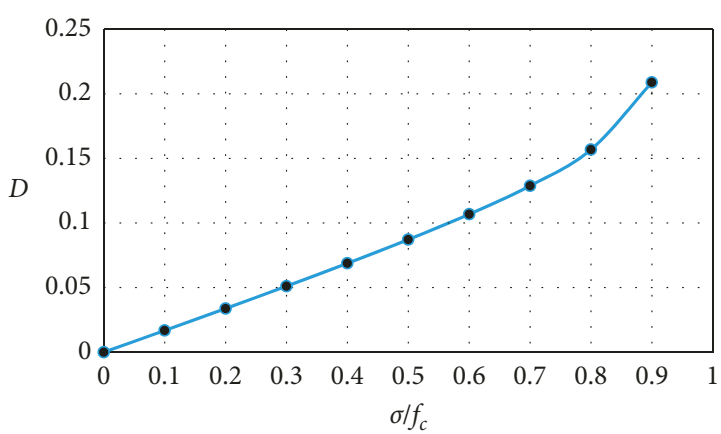

FIGURE 10: Damage index versus sustained stress in nonlinear creep analysis.

and creep effects. In other words, a coefficient of 0.75 can be considered in calculating the shear strength of RC deep beams in order to capture the effects of shrinkage and nonlinear creep in the design. For shallow beams, $P_{\mathrm{f}}$ is equivalent to 0.05 , confirming the ineffectiveness of shrinkage and creep on their flexural strength.

In the ultimate load step, a constant load of $90 \%$ of the beam strength is applied to test the effect of shrinkage and creep at a high-stress level. The results are shown in Figure 11.

These results confirm that shrinkage and nonlinear creep play an important role in shear strength of RC deep beams. Shrinkage along with creep accelerates the failure of deep beams. According to Figure 11, the collapse probability increases when a/d decreases. It seems that, in high-level sustained loading, the role of nonlinear creep can hardly be distinguished from that of shrinkage, as both of them cause collapse in a very high-level loading. In shallow beams, shrinkage has no effect on flexural strength, and all beams are damaged by nonlinear creep. Based on the results shown in Figure 11, a safety factor between 1.7 and 1.8 can be considered for preventing shear failure in RC deep beams subjected to the high loading level. On the contrary, a strength reduction coefficient of 0.2 can be used for calculating the shear strength of RC deep beams. Sudden drops because of transition from shallow to deep beams are again notable. It is because of the difference between the two types of beams. In beams with $a / d=0.5-2$, the principal failure is shear-dominant, while in beams with $a / d$ values greater than 

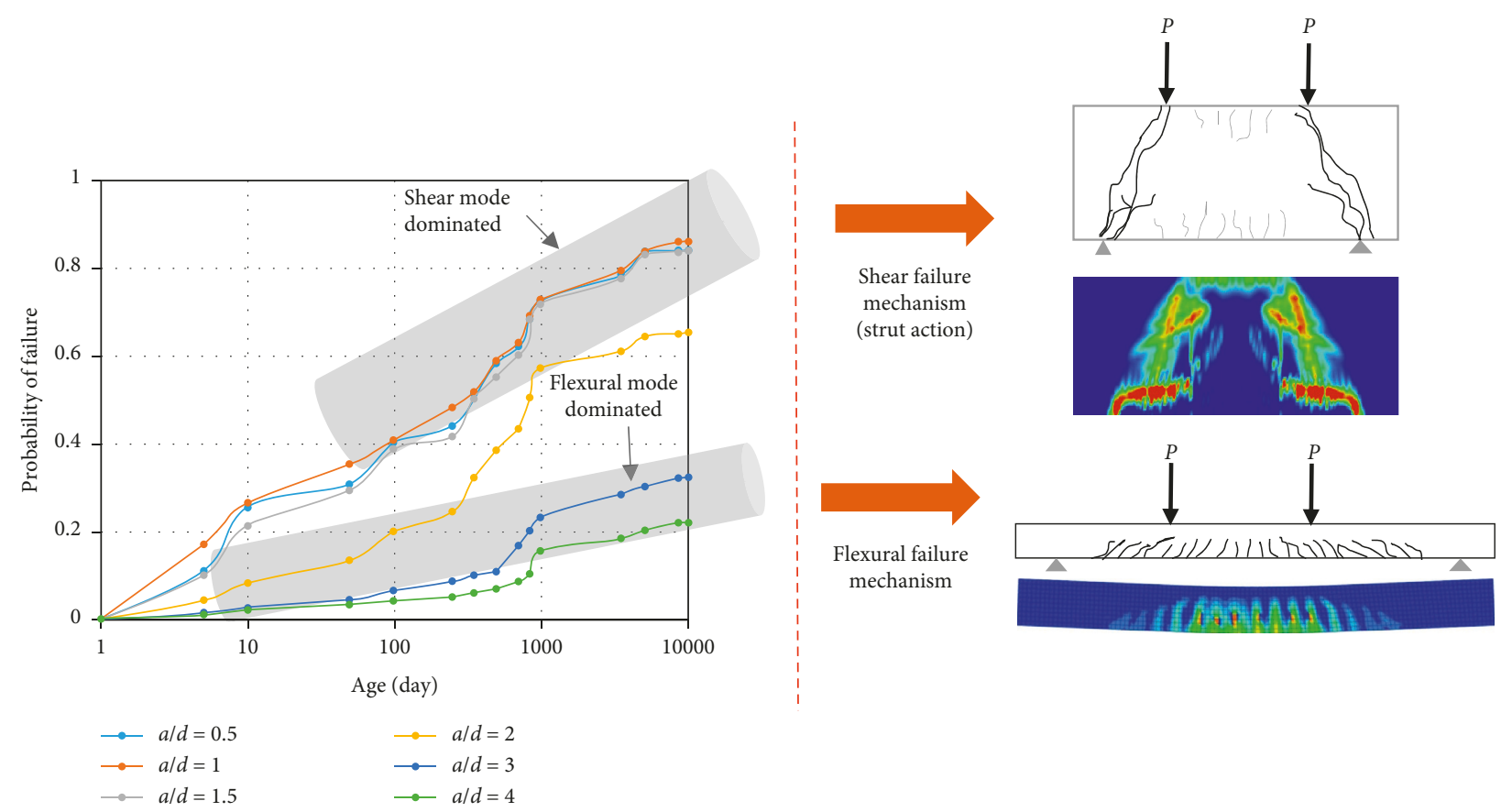

FIgURE 11: Collapse probabilities of RC beams in the strength limit state at a load level of $P=90 \%$ of the beam strength, $L=3 \mathrm{~m}$.

2, flexural failure may occur. In the shear-dominated case, shrinkage and nonlinear creep play an important role.

\section{Conclusion}

This paper presented a time-dependent reliability analysis of deep concrete beams with a special attention to linear/ nonlinear creep and shrinkage. Because of the lack of experimental results for RC deep beams considering creep and shrinkage, FEM analysis was carried out by ABAQUS software with ANFIS employed to obtain the data required for time-dependent reliability analysis. Monte Carlo simulation was used to determine the probabilities of failure. The results indicated that ANFIS was a powerful tool in the prediction of deflection as well as shear and flexural strengths of RC beams. In addition, the following conclusions could be drawn:

(1) It was found that shear-dominated behavior of the deep beam played an important role in the failure probability of RC beams in the serviceability limit state. Reduction in a/d resulted in a higher safety margin in the final long-term deflection. Also, more than fivefold increase was observed in the failure probability for shallow beams. Thus, RC beams with a higher a/d ratio in the presence of creep and shrinkage exhibited far lower reliability levels than deep beams in the serviceability limit state. Generally, within the linear creep range, exceedance probability of the beam deflection limit was as low as about 0.18 . The results of the analyses indicated that, by considering the shrinkage effect, a safety factor within 1.2 1.3 could be applied. For a practical calculation, a reduction coefficient between 0.8 and
0.7 could be considered for the shear strength of RC deep beams.

(2) In the strength limit state, shrinkage and nonlinear creep effects led to greater collapse probability, especially in RC deep beams. In comparison with shallow beams, the effect of shrinkage was more pronounced (shrinkage increased the probability of failure by more than 4 times). One reason could be the difference in failure patterns of shallow and deep beams. When the concrete beam was affected by shrinkage, development of cracks in full depth could cause reduction in the shear strength. Thus, the collapse probability rose in the presence of shrinkage. The analysis results indicated that a safety factor of 1.7 1.8 was required to prevent the risk of shear failure in a high-level sustained loading of RC deep beams. For medium and low load levels, it was not necessary to consider an additional safety factor to prevent flexural or shear failure.

Based on the current study, the following prospective for future researches can be suggested:

(1) The time-dependent reliability analysis has been verified using two-stage verifications, but the specific experimental evidence on long-term behavior of RC deep beams can be carried out to enhance this investigation

(2) More investigations shall be carried out to study the effect of other parameters such as temperature on time-dependent reliability of concrete structures

(3) Proposing a new formulation for long-term deflection of RC deep beams may be a potential alternative for future exploration 


\section{Data Availability}

The data used to support the findings of this study are available from the corresponding author upon request.

\section{Conflicts of Interest}

The authors declare that they have no conflicts of interest.

\section{References}

[1] F. K. Kong, Reinforced Concrete Deep Beams, Taylor \& Francis Books, Abingdon, UK, 1st edition, 2002.

[2] R. I. Gilbert and G. Ranzi, Time-Dependent Behavior of Concrete Structures, Spon Press, New York, NY, USA, 2011.

[3] E. Hamed, "Modelling of creep in continuous RC beams under high levels of sustained loading," Mechanics of TimeDependent Materials, vol. 18, no. 3, pp. 589-609, 2014.

[4] M. Ghabdian, S. B. Beheshti-Aval, and A. Vafai, "Effect of creep on high-order shear deformable beams," Scientia Iranica, 2019.

[5] J. Xiao, L. Li, V. W. Y. Tam, and H. Li, "The state of the art regarding the long-term properties of recycled aggregate concrete," Structural Concrete, vol. 15, no. 1, pp. 3-12, 2014.

[6] W.-C. Choi and H.-D. Yun, "Long-term deflection and flexural behavior of reinforced concrete beams with recycled aggregate," Materials \& Design, vol. 51, pp. 742-750, 2013.

[7] R. I. Gilbert and S. Nejadi, "An experimental study of flexural cracking in reinforced concrete members under sustained loads," University Report No. R-435, p. 59, University of New South Wales, Sydney, Australia, 2004.

[8] N. Reybrouck, P. Criel, T. Van Mullem, and R. Caspeele, "Long-term data of reinforced concrete beams subjected to high sustained loads and simplified prediction method," Structural Concrete, vol. 18, no. 6, pp. 850-861, 2017.

[9] Z. Pan and S. Meng, "Three-level experimental approach for creep and shrinkage of high-strength high-performance concrete," Engineering Structures, vol. 120, pp. 23-36, 2016.

[10] Z. P. Bažant and S. T. Wu, "Creep and shrinkage law for concrete at variable humidity," ASCE Journal of the Engineering Mechanics Division, vol. 100, no. 6, pp. 1183-1209, 1974.

[11] F. Akgül and D. M. Frangopol, "Computational platform for predicting lifetime system reliability profiles for different structure types in a network," Journal of Computing in Civil Engineering, vol. 18, no. 2, pp. 92-104, 2004.

[12] M. Sigit Darmawan and M. G. Stewart, "Spatial time-dependent reliability analysis of corroding pretensioned prestressed concrete bridge girders," Structural Safety, vol. 29, no. 1, pp. 16-31, 2007.

[13] A. A. Czarnecki and A. S. Nowak, "Time-variant reliability profiles for steel girder bridges," Structural Safety, vol. 30, no. 1, pp. 49-64, 2008.

[14] C. Q. Li and R. E. Melchers, "Reliability analysis of creep and shrinkage effects," Journal of Structural Engineering, vol. 118, no. 9, pp. 2323-2337, 1992.

[15] M. G. Stewart, "Serviceability reliability analysis of reinforced concrete structures," ASCE Journal of Structural Engineering, vol. 122, no. 7, pp. 794-803, 1996.

[16] T. Guo, R. Sause, D. M. Frangopol, and A. Li, "Time-dependent reliability of PSC box-girder bridge considering creep, shrinkage, and corrosion," ASCE Journal of Bridge Engineering, vol. 16, no. 1, pp. 29-43, 2011.
[17] Y. S. Ma and Y. F. Wang, "Creep effects on the reliability of a concrete-filled steel tube arch bridge," ASCE Journal of Bridge Engineering, vol. 18, no. 10, pp. 1095-1104, 2013.

[18] T. Xu, A. Castel, and R. I. Gilbert, "On the reliability of serviceability calculations for flexural cracked reinforced concrete beams," Structures, vol. 13, pp. 201-212, 2018.

[19] P. Lu, S. Chen, and Y. Zheng, "Artificial intelligence in civil engineering," Mathematical Problems in Engineering, vol. 2012, Article ID 145974, 22 pages, 2012.

[20] A. Ghorbani and M. R. Ghasemi, "Reliability and sensitivity analysis of structures using adaptive neuro-fuzzy systems," Journal of Rehabilitation in Civil Engineering, vol. 7, no. 1, pp. 152-165, 2019.

[21] L. Bal and F. Buyle-Bodin, "Artificial neural network for predicting creep of concrete," Neural Computing and Applications, vol. 25, no. 6, pp. 1359-1367, 2014.

[22] T. Bilir, O. Gencel, and I. B. Topcu, "Prediction of restrained shrinkage crack widths of slag mortar composites by Takagi and Sugeno ANFIS models," Neural Computing and Applications, vol. 27, no. 8, pp. 2523-2536, 2016.

[23] U. Pendharkar, K. A. Patel, S. Chaudhary, and A. K. Nagpal, "Closed-form expressions for long-term deflections in highrise composite frames," International Journal of Steel Structures, vol. 17, no. 1, pp. 31-42, 2017.

[24] F. M. S. Al-Zwainy, R. I. K. Zaki, A. M. Al-Saeedi, and H. F. Ibraheem, "Validity of artificial neural modeling to estimate time-dependent deflection of reinforced concrete beams," Cogent Engineering, vol. 5, no. 1, pp. 1-15, 2018.

[25] A. Sadrmomtazi, J. Sobhani, and M. A. Mirgozar, "Modeling compressive strength of EPS lightweight concrete using regression, neural network and ANFIS," Construction and Building Materials, vol. 42, pp. 205-216, 2013.

[26] M. Mohammadhassani, H. Nezamabadi-Pour, J. MohdZamin, M. Jameel, S. J. S. Hakim, and M. Zargar, "Application of the ANFIS model in deflection prediction of concrete deep beam," Structural Engineering and Mechanics, vol. 45, no. 3, pp. 319-332, 2013.

[27] A. Huber and R. Rasia, "Effect of creep on the flexural strength and deformation of concrete beams," Ein Dienst der ETHBibliothek, vol. 22, pp. 332-345, 1970.

[28] M. Fernández Ruiz, A. Muttoni, and P. G. Gambarova, "Relationship between nonlinear creep and cracking of concrete under uniaxial compression," Journal of Advanced Concrete Technology, vol. 5, no. 3, pp. 383-393, 2007.

[29] Z. P. Bažant and J. K. Kim, "Improved prediction model for time-dependent deformations of concrete: part 2-basic creep," Materials and Structures, vol. 24, no. 6, pp. 409-421, 1991.

[30] Q. Yu, Z. P. Bažant, and R. Wendner, "Improved algorithm for efficient and realistic creep analysis of large creep-sensitive concrete structures," ACI Structural Journal, vol. 109, no. 5, pp. 665-675, 2012.

[31] ACI 209.2R-08, "Guide for modeling and calculating shrinkage and creep in hardened concrete," in ACI Manual of Concrete Practice, ACI, Farmington Hills, MI, USA, 2008.

[32] Comite Ero-International du Beton (CEB), CEB-FIP Model Code for Concrete Structures, Comite Ero-International du Beton, Lausanne, Switzerland, 1990.

[33] Japan Society of Civil Engineers (JSCE) Model, Standard Specification for Concrete Structures, Japan Society of Civil Engineers, Tokyo, Japan, 2010.

[34] N. J. Gardner and M. J. Lockman, "Design provisions for drying shrinkage and creep of normal strength concrete," ACI Materials Journal, vol. 98, no. 2, pp. 159-167, 2001. 
[35] Z. P. Bazant and S. Baweja, "Justification and refinements of model B3 for concrete creep and shrinkage 2. Updating and theoretical basis," Materials and Structures, vol. 28, no. 7, pp. 415-430, 1995.

[36] I. H. Yang, "Uncertainty and sensitivity analysis of timedependent effects in concrete structures," Engineering Structures, vol. 29, no. 7, pp. 1366-1374, 2007.

[37] J. Lubliner, J. Oliver, S. Oller, and E. Oñate, "A plastic-damage model for concrete," International Journal of Solids and Structures, vol. 25, no. 3, pp. 299-326, 1989.

[38] R. I. Gilbert, Calculation of Long-Term Deflection, CIA Seminar, Brisbane, Australia, 2008.

[39] M. R. Salamy, H. Kobayashi, and S. Unjoh, "Experimental and analytical study on RC deep beams," Asian Journal of Civil Engineering (Building and Housing), vol. 6, no. 5, pp. 409-422, 2005.

[40] ABAQUS User Manual V6, 11M Dassault Systems 2004-2016.

[41] American Concrete Institute, Building Code Requirements for Structural Concrete (ACI 318-14), American Concrete Institute, Farmington Hills, MI, USA, 2014.

[42] J.-S. R. Jang, "ANFIS: adaptive-network-based fuzzy inference system," IEEE Transactions on Systems, Man, and Cybernetics, vol. 23, no. 3, pp. 665-685, 1993.

[43] R. I. Navarro, "Study of a neural network-based system for stability augmentation of an airplane," Report, Universitat Politecnica de Catalunya, Barcelona, Spain, 2013.

[44] M. Şahin and R. Erol, "A comparative study of neural networks and ANFIS for forecasting attendance rate of soccer games," Mathematical and Computational Applications, vol. 22, no. 4, pp. 1-12, 2017.

[45] B. Ahmadi-Nedushan, "Prediction of elastic modulus of normal and high strength concrete using ANFIS and optimal nonlinear regression models," Construction and Building Materials, vol. 36, pp. 665-673, 2012.

[46] M. Şahin and R. Erol, "Prediction of attendance demand in European football games: comparison of ANFIS, fuzzy logic, and ANN," Computational Intelligence and Neuroscience, vol. 2018, Article ID 5714872, 14 pages, 2018.

[47] M. Papadrakakis and N. D. Lagaros, "Reliability-based structural optimization using neural networks and Monte Carlo simulation," Computer Methods in Applied Mechanics and Engineering, vol. 191, no. 3, pp. 3491-3507, 2002.

[48] H. Hyodo, R. Sato, K. Kawai, and H. Nakayama, "Effects of drying shrinkage on shear tension strength of reinforced concrete beams," in Proceedings of the International Conference on Fracture Mechanics of Concrete and Concrete Structures, Toledo, Spain, March 2009.

[49] C. Mazzoti and M. Savoia, "Nonlinear creep, poisson's ratio, and creep-damage interaction of concrete in compression," ACI Materials Journal, vol. 99, no. 5, pp. 450-457, 2002. 


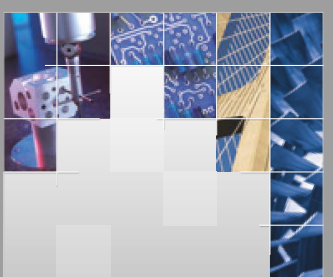

\section{Enfincering}
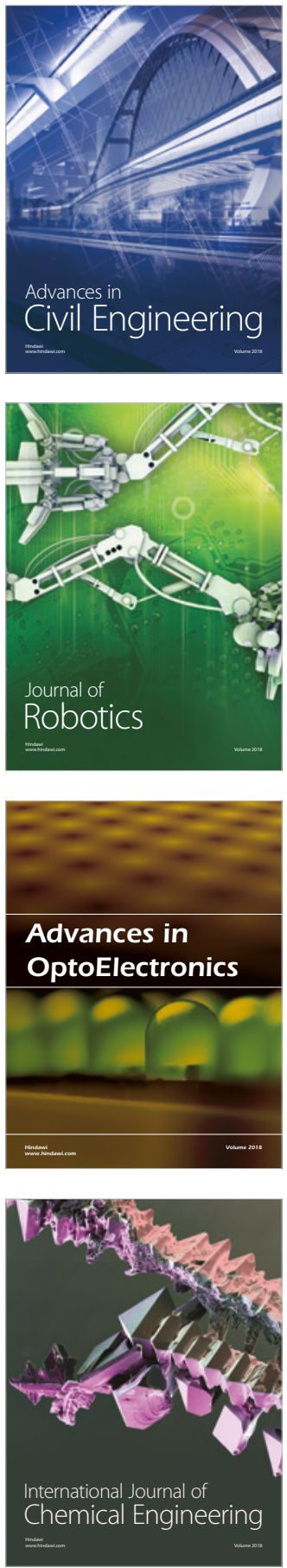

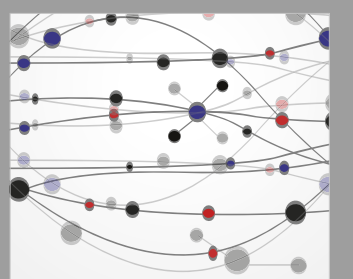

\section{Rotating \\ Machinery}

The Scientific World Journal

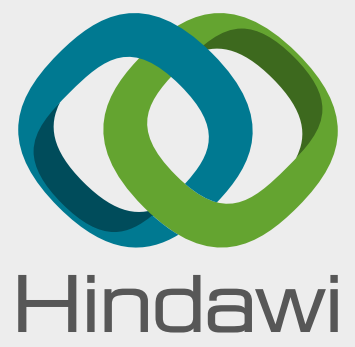

Submit your manuscripts at

www.hindawi.com
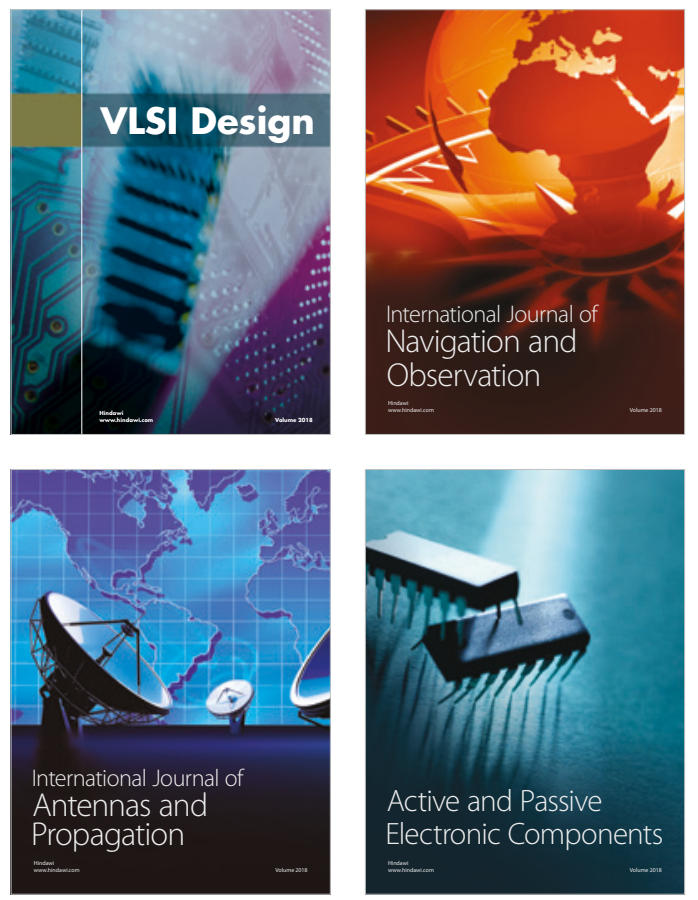
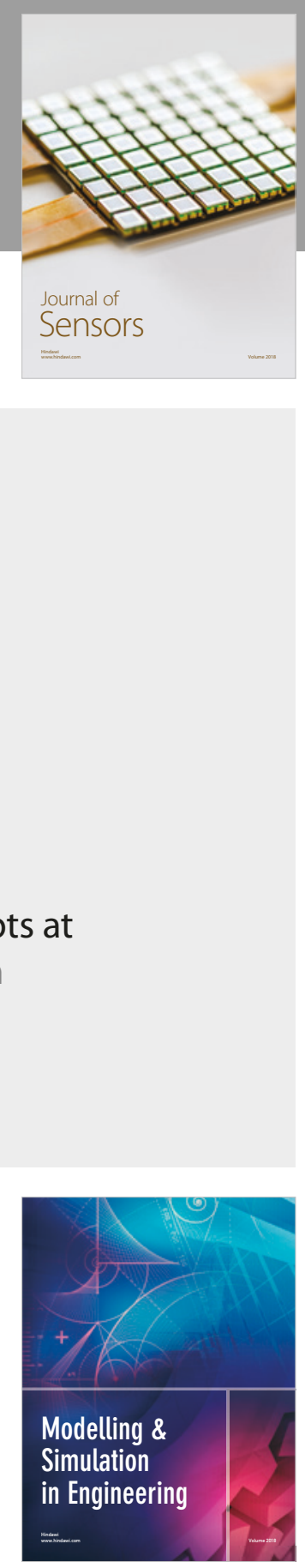

\section{Advances \\ Multimedia}
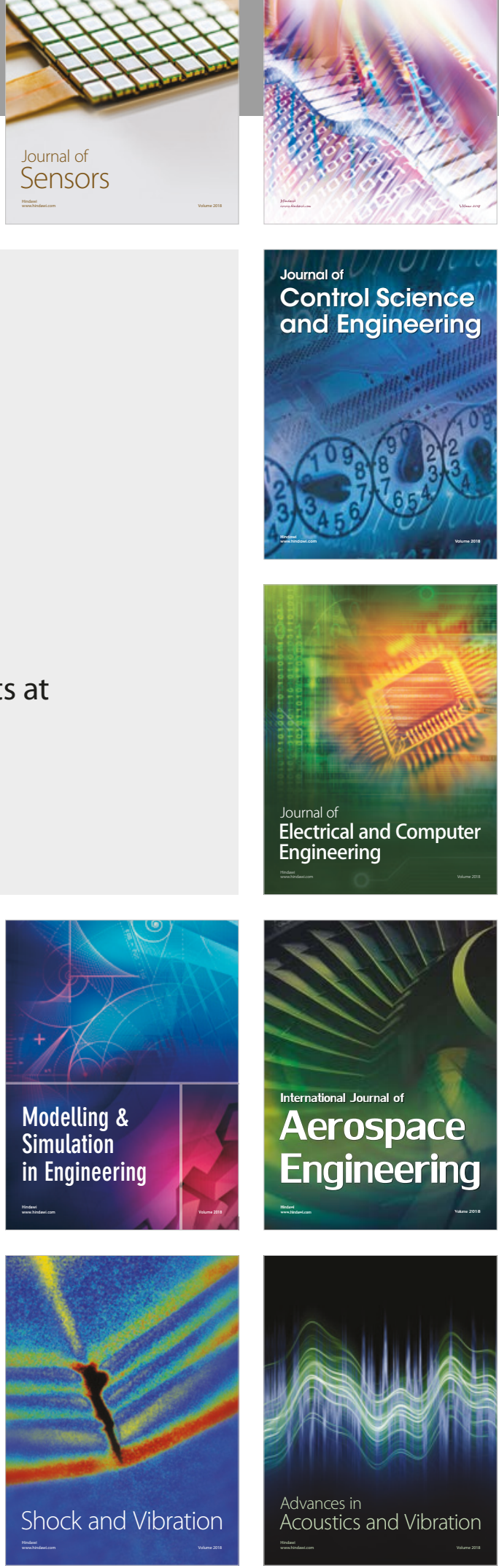